\title{
A Study of Through-Space and Through-Bond $J(P P)$ Coupling in a Rigid Non-Symmetrical Bis(phosphine) and its Metal Complexes
}

Brian A. Chalmers, ${ }^{a}$ Phillip S. Nejman, ${ }^{a}$ Alice V. Llewellyn, ${ }^{a}$ Adrian M. Felaar, ${ }^{a}$ Ben L. Griffiths, ${ }^{a}$ Eden I. Portman, ${ }^{a}$ Emma-Jane L. Gordon, ${ }^{a}$ Kenny J. H. Fan, ${ }^{a}$ J. Derek Woollins, ${ }^{a}$ M. Bühl, ${ }^{a}$ Olga L. Malkina, ${ }^{b}$ David B. Cordes, ${ }^{a}$ Alexandra M. Z. Slawin, ${ }^{a}$ Petr Kilian*a

${ }^{a}$ EaStChem School of Chemistry, University of St Andrews, St Andrews, Fife KY16 9ST, UK. Email: pk7@standrews.ac.uk

${ }^{b}$ Slovak Academy of Sciences, Institute of Inorganic Chemistry, Dúbravská cesta 9, 84536 Bratislava, Slovakia

\begin{abstract}
A series of representative late $d$-block metal complexes bearing a rigid bis(phosphine) ligand, $i \operatorname{Pr}_{2} \mathrm{P}-\mathrm{Ace}$ $\mathrm{PPh}_{2}(\mathbf{L}$, Ace $=$ acenaphthene-5,6-diyl), was prepared and fully characterised by various techniques, including multinuclear NMR and single crystal X-ray diffraction. The heteroleptic nature of the perisubstituted ligand $\mathbf{L}$ allows for the direct observation of the $J_{\mathrm{PP}}$ couplings in the ${ }^{31} \mathrm{P}\left\{{ }^{1} \mathrm{H}\right\} N \mathrm{NMR}$ spectra. Magnitudes of $J_{\mathrm{PP}}$ are correlated with the identity and geometry of the metal, and the distortions of the ligand $\mathbf{L}$. The forced overlap of the phosphine lone pairs due to the constraints imposed by the rigid acenaphthene skeleton in $\mathbf{L}$ results in large ${ }^{4} J_{\mathrm{pp}}$ of $180 \mathrm{~Hz}$. Sequestration of the lone pairs, either via oxidation of the phosphine, or metal chelation, results in distinct changes in the magnitude of $J_{\mathrm{pp}}$. For tetrahedral $d^{10}$ complexes $\left(\left[\mathrm{LMCl}_{2}\right], \mathrm{M}=\mathrm{Zn}, \mathrm{Cd}, \mathrm{Hg}\right)$, the $J_{\mathrm{PP}}$ is comparable or larger $(193-309 \mathrm{~Hz})$ to that in free ligand $\mathbf{L}$, although the P...P separation in these complexes is increased by $c a$. $0.4 \AA$ (compare to free ligand $\mathbf{L}$ ). The magnitude of $J_{\mathrm{PP}}$ diminishes to $26-117 \mathrm{~Hz}$ in square planar $d^{8}$ complexes ([LMX $\left.\mathbf{L}_{2}\right], \mathrm{M}=$ $\mathrm{Ni}, \mathrm{Pd}, \mathrm{Pt}, \mathrm{X}=\mathrm{Cl}, \mathrm{Br}$ ) and octahedral $\mathrm{Mo}^{0}$ complex $\left[\mathrm{LMo}(\mathrm{CO})_{4}\right], 33 \mathrm{~Hz}$ ). Coupling Deformation Density calculations indicate the through-space interaction dominates in free $\mathbf{L}$, whilst in metal complexes the main coupling pathway is via the metal atom.
\end{abstract}




\section{Introduction}

1,8-Bis(diphenylphosphino)naphthalene (dppn, Figure 1) represents one of the archetypal bidentate ligands in transition metal coordination chemistry. ${ }^{1}$ Its hallmarks are exceptional rigidity, and a close proximity of the two phosphine donor atoms. The P...P separation in dppn is $3.05 \AA^{2},{ }^{2}$ which represents $78 \%$ of the sum of the van der Waals radii. ${ }^{3}$ This results in a bite angle of the free ligand of $c a .90^{\circ} .{ }^{4} \mathrm{~A}$ number of metal complexes of dppn have been reported, and the coordination chemistry of dppn and related ligands has been covered in our recent review. ${ }^{1}$ In the majority of cases, chelation of a metal ion is accompanied by a slight lengthening of the P...P distance, with slight increase in the distortion of the naphthalene skeleton also observed..$^{1,4}$

Several related 1,8-bis(phosphino)naphthalenes with substituents other than phenyl have been synthesised; however, their number is somehow restricted due to the limited commercial availability, or lack of facile synthetic routes to the required precursor diorganohalophosphines. Steric constraints associated with peri-substitution represent another limitation, some functionalities being too large to occupy both peri-sites simultaneously. . $^{5-11}$

There are only few reports of peri-bis(phosphines) with a non-symmetrical substitution pattern; i.e. where two differently functionalised $\mathrm{P}(\mathrm{III})$ centres occupy the peri-positions of naphthalene (or related polycyclic aromatic scaffolds, acenaphthene and anthracene). Whilst 1,8-dibromonaphthalene lends itself as an excellent precursor for stepwise lithium-halogen exchange to introduce two different phosphine groups to the peri-region, its synthesis is challenging and poor yielding. ${ }^{11-12}$ In contrast, 5,6dibromoacenaphthene is synthetically accessible on a multi-gram scale from the reaction of acenaphthene and $\mathrm{N}$-bromosuccinimide, and also allows for stepwise lithium-halogen exchange. ${ }^{13-14}$ Adoption of 5,6-dibromoacenaphthene as a principal synthon in our group has led to the isolation of a large variety of systems showing stabilisation arising from peri-substitution (using so called "enforcedproximity donor stabilisation"), ${ }^{15-17}$ and also allowed for the facile synthesis of a compound central to this work, the bis(phosphine) $\operatorname{PiPr}_{2}-A c e-\mathrm{PPh}_{2}\left(\mathrm{~L}, \mathrm{Ace}=\right.$ acenaphthene-5,6-diyl). ${ }^{18}$ The non-symmetrical nature of $L$ allows for the direct observation of homonuclear spin-spin coupling via ${ }^{31} P\left\{{ }^{1} \mathrm{H}\right\} N M R$ spectroscopy. Thus, the interaction between the two chemically (and magnetically) differing phosphorus atoms in a variety of metal complexes can be probed and assessed with respect to the free ligand, and also with respect to the P-oxidised ligand. 
<smiles>c1ccc(P(c2ccccc2)c2cccc3cccc(P(c4ccccc4)c4ccccc4)c23)cc1</smiles>

$J_{\mathrm{PP}}=199 \mathrm{~Hz}$

(from SS NMR)

dppn

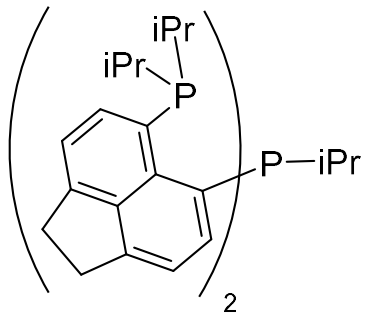

$J_{P P}=94-142 \mathrm{~Hz}$

(ABC spin system, two rotamers at low

temperature)

C<smiles></smiles>

E<smiles>COP(c1ccccc1)c1cccc2cccc(P(N(C)C)N(C)C)c12</smiles>

$J_{\mathrm{PP}}=246 \mathrm{~Hz}$

A<smiles>CCCc1cccc2cc3cccc(P(C)C)c3c(P(N(C)C)N(C)C)c12</smiles>

$J_{\mathrm{PP}}=191 \mathrm{~Hz}$

D

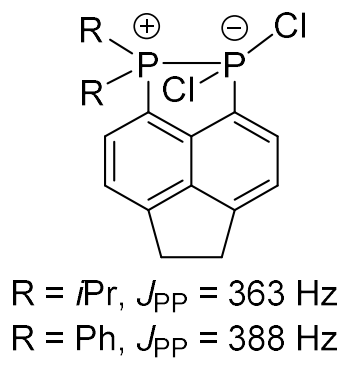

$F$

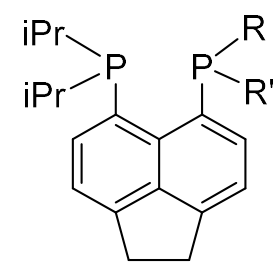

$\mathrm{R}=\mathrm{R}^{\prime}=\mathrm{H}, J_{\mathrm{PP}}=205 \mathrm{~Hz}$

$\mathrm{R}=\mathrm{H}, \mathrm{R}^{\prime}=\mathrm{Ph}, J_{\mathrm{PP}}=169 \mathrm{~Hz}$

$\mathrm{R}=\mathrm{H}, \mathrm{R}^{\prime}=\mathrm{Fc}, J_{\mathrm{PP}}=199 \mathrm{~Hz}$

$\mathrm{R}=\mathrm{Ph}, \mathrm{R}^{\prime}=\mathrm{Me}, J_{\mathrm{PP}}=169 \mathrm{~Hz}$

$\mathrm{R}=\mathrm{Ph}, \mathrm{R}^{\prime}=\mathrm{Fc}, J_{\mathrm{PP}}=162 \mathrm{~Hz}$

$\mathrm{R}=\mathrm{Ph}, \mathrm{R}^{\prime}=\mathrm{iPr}, J_{\mathrm{PP}}=160 \mathrm{~Hz}$

$\mathrm{R}=\mathrm{R}^{\prime}=(\mathrm{OPh}), J_{\mathrm{PP}}=199 \mathrm{~Hz}$

$\mathrm{L}: \mathrm{R}=\mathrm{R}^{\prime}=\mathrm{Ph}, J_{\mathrm{PP}}=180 \mathrm{~Hz}$

B

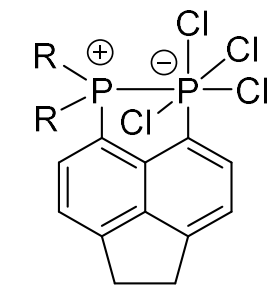

$J_{P P}=88-118 \mathrm{~Hz}$

(temperature dependent)

G

Figure 1: Peri-bis(phosphines) with non-symmetrical substitution pattern.

As alluded to above, only handful of non-symmetrical peri-substituted bis(phosphines) have been reported to date. These are listed in Figure $1(\mathbf{A}-\mathbf{D})$, together with the relevant $J_{\mathrm{PP}}$ coupling constants. ${ }^{18-}$ ${ }^{25}$ While the $J_{\mathrm{PP}}$ magnitude in A-D changes with different substituents (and the backbone), in all cases it remains rather substantial, and comparable to ${ }^{1} J_{\mathrm{PP}}$ observed in $\sigma^{3} \mathrm{P}-\sigma^{3} \mathrm{P}$ bonded species $\mathbf{E}\left(J_{\mathrm{PP}}=220 \mathrm{~Hz}\right)$. A higher magnitude of $J_{\mathrm{PP}}$ was found in $\sigma^{4} \mathrm{P}-\sigma^{4} \mathrm{P}$ dative-bonded $\mathbf{F}\left(J_{\mathrm{PP}}=363\right.$ and $\left.388 \mathrm{~Hz}\right),{ }^{14}$, ${ }^{26}$ whilst significantly smaller couplings were observed in the $\sigma^{4} \mathrm{P}-\sigma^{6} \mathrm{P}$ dative-bonded $\mathbf{G}\left(J_{\mathrm{PP}}\right.$ varied from $88 \mathrm{~Hz}$ at $213 \mathrm{~K}$ to $118 \mathrm{~Hz}$ at $303 \mathrm{~K}$ ). It is believed that the JPP coupling in A-D comprises entirely of a 'through space' interaction in which the spin information is transmitted between the coupled nuclei via the non-bonding interaction of two phosphorus lone-pair orbitals.

In the past, the $J_{\mathrm{Pp}}$ of phosphine-metal complexes with chemically identical phosphine groups, were determined using complex double resonance techniques via the ${ }^{1} \mathrm{H}$ NMR spectra, ${ }^{27}$ or utilising the inequivalence of the two phosphorus atoms in the solid state by solid state NMR techniques. ${ }^{2}$ Direct observation of significant $J_{\mathrm{PP}}$ through-space coupling has been reported for a series of tetraphosphine ferrocenyl species by Hierso, ${ }^{28}$ and the wider area has been reviewed recently. ${ }^{29}$ Here we relate the 
directly observed through-space couplings across the peri-gap, with their through-metal counterparts. Furthermore, we relate these with observed structural parameters (obtained from single crystal X-ray diffraction) and also with monoxidised $\left(\mathrm{L}^{\circ}\right)$ and dioxidised $\left(\mathrm{L}^{\mathbf{0 2}}\right)$ versions of the free ligand.

\section{Results \& Discussion}

\section{Syntheses}

The bis(phosphine) ligand $\mathbf{L}$ was synthesised according to the published procedure ${ }^{18}$ from 5 -bromo-6(diisopropylphosphino)acenaphthene ( $\left(\mathrm{Pr}_{2} \mathrm{P}-\mathrm{Ace}-\mathrm{Br}\right)$, in which a low temperature lithium halogen exchange was followed by $\mathrm{P}-\mathrm{C}$ coupling with $\mathrm{Ph}_{2} \mathrm{PCl}$ and aqueous work-up. This gives $\mathbf{L}$ as a moderately air sensitive yellow solid in good yields. Under aerobic conditions, powdered $\mathbf{L}$ shows signs of reaction to its respective phosphine oxides only after several days, though oxidation occurs more rapidly ( $<1$ day) in solution. Hence as a precaution, all reactions involving free ligand were performed under a nitrogen or argon atmosphere using Schlenk/glove box techniques and degassed solvents. A general synthetic procedure involved preparation of a solution or suspension of $L$, to which a solution of the metal containing precursor was added dropwise. Removal of the volatiles in vacuo afforded the desired complexes. The syntheses are summarised in Scheme 1. Where possible, all novel compounds were fully characterised by multinuclear NMR, HRMS (high resolution mass spectrometry), elemental analysis and IR spectroscopy.

Synthetic, structural and spectroscopic data of the platinum complex $\left[\mathrm{LPtCl}_{2}\right]$ as well as the structural data of ligand $\mathbf{L}$ have been reported by us earlier; ${ }^{18}$ for completeness we discuss these in the context of other related compounds in this paper. 


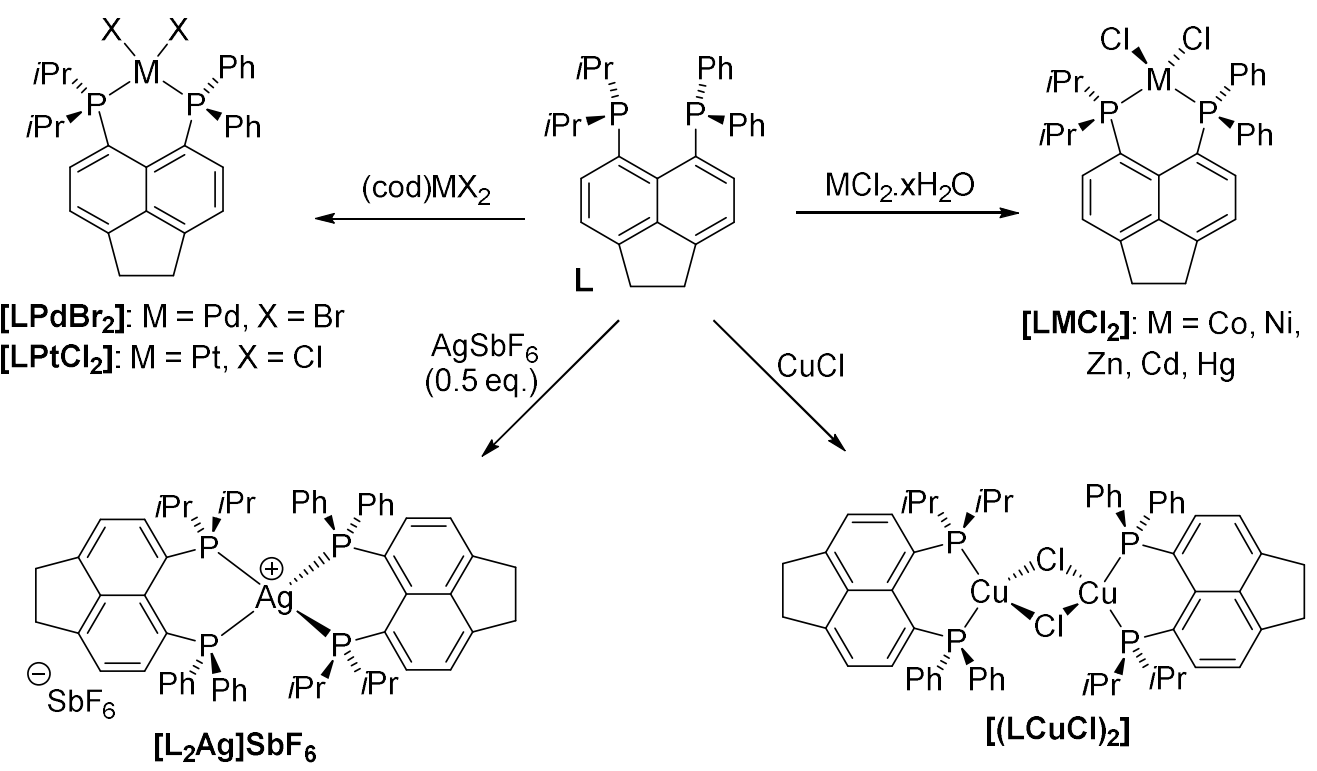

Scheme 1: Syntheses of metal complexes of bis(phosphine) ligand $\mathbf{L}$ reported in this work (cod $=1,5$ cyclooctadiene).

The reaction of $\mathbf{L}$ with half an equivalent of $\mathrm{AgSbF}_{6}$ leads to the formation of pale yellow $\left[\mathrm{L}_{2} \mathrm{Ag}\right] \mathrm{SbF}_{6}$; a mononuclear tetrahedral complex bearing two bidentate ligands $\mathbf{L}$, each bound in $\mathrm{K}^{2}$ manner. The reaction of $\mathbf{L}$ and cuprous chloride produces the dinuclear chloride bridged copper(I) complex, [( $\left.\mathrm{LCuCl})_{2}\right]$, as a pale yellow solid. All other complexes in Scheme 1 are mononuclear with one $\mathrm{K}^{2}-\mathrm{L}$ ligand chelating to the metal, which adopts either a tetrahedral geometry ( $\mathrm{Co}, \mathrm{Zn}, \mathrm{Cd}, \mathrm{Hg}$ ) or cis configuration in approximate square planar geometry ( $\mathrm{Ni}, \mathrm{Pd}, \mathrm{Pt})$. The Pt complex, [ $\left.\mathrm{LPtCl}_{2}\right]$, and the group 12 complexes, [ $\left.\mathrm{LZnCl}_{2}\right],\left[\mathrm{LCdCl}_{2}\right]$ and $\left[\mathrm{LHgCl}_{2}\right]$, are colourless, while the $\mathrm{Ni}(\mathrm{II})$ complex, [ $\left.\mathrm{LNiCl}_{2}\right]$, is red, the Co(II) complex, $\left[\mathrm{LCOCl}_{2}\right]$, is green and both $\left[\mathrm{LPdBr}_{2}\right]$ and $\left[(\mathrm{LCuCl})_{2}\right]$ are yellow. All complexes shown in Scheme 1 are air stable both in the solid state and in solution, with the exception of the cobalt(II) complex, [ $\left.\mathrm{LCoCl}_{2}\right]$. The cobalt complex undergoes monooxidation of its bis(phosphine) ligand on dissolution in nondegassed solvents, this is accompanied with a colour change from green to blue. This transformation occurs fastest in acetonitrile (ca. 120 seconds - see Supporting Info, Figures S10 and S11). Removal of the solvent under reduced pressure yields $\left[\mathrm{L}^{\circ} \mathrm{CoCl}_{2}\right]$ as a blue powder in a quantitative yield. Single crystal Xray diffraction confirmed that the $\mathrm{PPh}_{2}$ group has been selectively oxidised to a $\mathrm{P}(\mathrm{O}) \mathrm{Ph}_{2}$ moiety and the resulting monoxide ligand $L^{\circ}$ remains $\mathrm{K}^{2}-\mathrm{P}^{\prime \prime \prime}, \mathrm{O}$ bonded to cobalt atom, forming a seven-membered $\mathrm{C}_{3} \mathrm{P}_{2} \mathrm{OCo}$ metallacycle (see Scheme 2).

Interestingly, dissolution of $\left[\mathrm{L}^{\circ} \mathrm{CoCl}_{2}\right]$ in methanol results in a loss of the $\mathrm{L}^{\mathrm{O}}$ ligand from the complex, giving a pink solution instantaneously. Leaving the solution to stand for 24 hours led to formation of colourless crystals, which were isolated and identified as the free bis(phosphine)monoxide $\mathbf{L}^{\circ}$. The remaining $\mathrm{CoCl}_{2}$, dissociated from the ligand, stayed in the methanolic solution. 


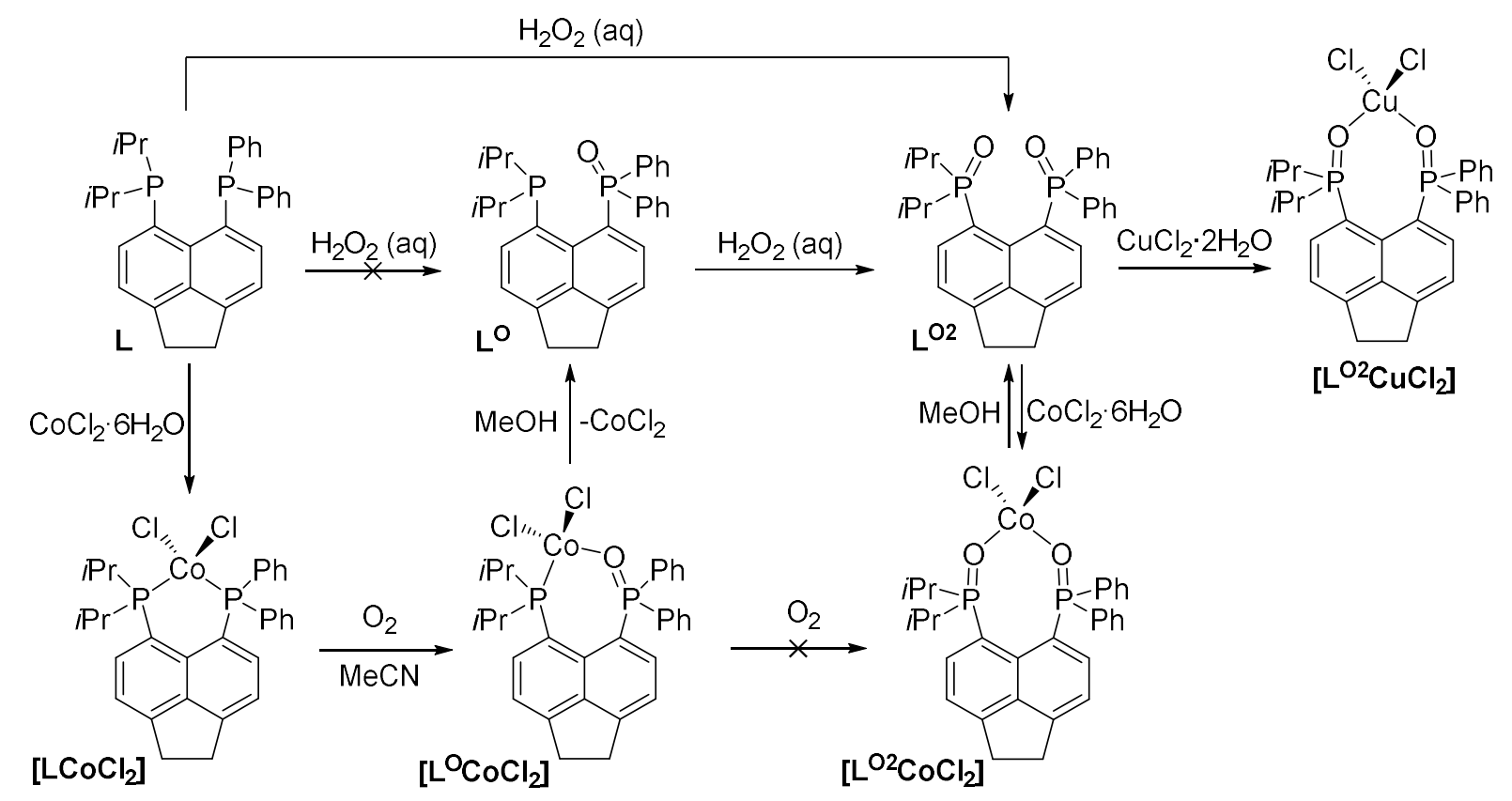

Scheme 2: Oxidation reactions involving $\mathrm{L}$ as a free or metal-bound ligand, and the formation of $\left[\mathrm{L}^{\mathrm{O}} \mathrm{CoCl}_{2}\right]$ and $\left[\mathrm{L}^{\mathrm{O}} \mathrm{CuCl}_{2}\right]$.

Bis(phosphine) monoxide (BPMO) ligands are used widely in catalytic applications such as Diels-Alder couplings, ${ }^{30}$ sulfoxidations ${ }^{30}, \mathrm{C}-\mathrm{C}$ bond formation ${ }^{31-32}$ and hydrogenations. ${ }^{33}$ Their synthesis is somewhat challenging as selective oxidation of one phosphine functionality is needed, whilst leaving the other intact. The synthetic pathways are often long, for example, the formation of $[\mathrm{RuCl}(\mathrm{BINAP}(\mathrm{O}))(\mathrm{bipy})] \mathrm{PF} \mathrm{P}_{6}$ (BINAP $=2,2$ '-bis(diphenylphosphino)-1,1'-binaphthyl, bipy $=2,2^{\prime}$-bipyridine), requires reaction to proceed for 14 days for a $70 \%$ yield. ${ }^{32,34}$ In comparison to the known methods for the synthesis of BPMOs, the approach shown in Scheme 2 is somewhat simpler and essentially quantitative at each step with 100 $\%$ chemoselectivity observed. Moreover, the progress of the reaction is very easily followed by observation of colour changes (Figure 2).

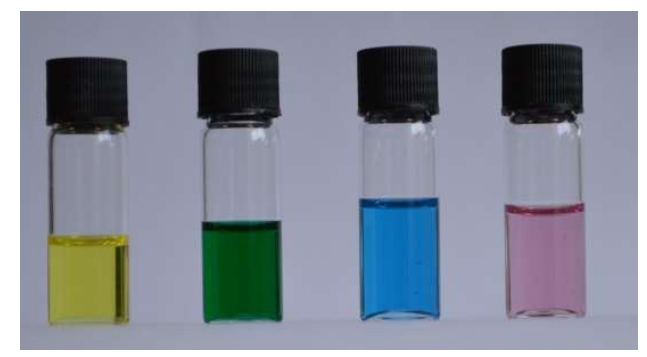

Figure 2: From left to right: the colours of $\mathrm{MeCN}$ solutions of $\mathbf{L}$ (yellow), $\left[\mathrm{LCoCl}_{2}\right]$ (green), [ $\left.\mathrm{L}^{\circ} \mathrm{CoCl}_{2}\right]$ (blue) and methanolic solution of $\mathrm{CoCl}_{2}$ (pink), obtained by dissolution of $\left[\mathrm{L}^{\circ} \mathrm{CoCl}_{2}\right]$, followed by removal of $\mathbf{L}^{\circ}$ by crystallisation. 
In an attempt to synthesise $\mathbf{L}^{\circ}$ from $\mathbf{L}$ in an alternative way, a solution of $\mathbf{L}$ in $\mathrm{CH}_{2} \mathrm{Cl}_{2}$ was treated with one molar equivalent of aqueous $\mathrm{H}_{2} \mathrm{O}_{2}$. Even with very slow addition, the bis(phosphine)oxide, $\mathrm{L}^{02}$ was the major product as judged by ${ }^{31} \mathrm{P}\left\{{ }^{1} \mathrm{H}\right\}$ NMR spectroscopy. Using a slight excess of hydrogen peroxide results in a complete conversion of $\mathbf{L}$ to $\mathbf{L}^{\mathbf{0 2}}$ (Scheme 2). A blue tetrahedral cobalt(II) complex, $\left[{ }^{02} \mathrm{CoCl}_{2}\right]$, was prepared by a quantitative reaction of $\mathrm{L}^{\mathbf{0 2}}$ with an equivalent of $\mathrm{CoCl}_{2} \cdot 6 \mathrm{H}_{2} \mathrm{O}$ (Scheme 2). In a similar vein to the $\left[\mathrm{L}^{\circ} \mathrm{CoCl}_{2}\right]$, addition of methanol to solid $\left[\mathrm{L}^{\mathrm{O}} \mathrm{CoCl}_{2}\right]$ produces a pink solution, from which $\mathbf{L}^{\mathbf{0 2}}$ and $\mathrm{CoCl}_{2}$ were isolated. Interestingly, no $\left[\mathrm{L}^{\mathrm{O} 2} \mathrm{CoCl}_{2}\right]$ was produced when $\left[\mathrm{LCoCl}_{2}\right]$ or $\left[\mathrm{L}^{\circ} \mathrm{CoCl}_{2}\right]$ (as acetonitrile solutions) were exposed to air at room temperature.

A yellow tetrahedral copper(II) complex $\left[\mathrm{L}^{\mathrm{O2}} \mathrm{CuCl}_{2}\right]$ was also prepared and isolated in a quantitative yield by the reaction of $\mathrm{L}^{\mathrm{O} 2}$ with $\mathrm{CuCl}_{2} \cdot 2 \mathrm{H}_{2} \mathrm{O}$.

\section{NMR Spectroscopy}

\section{Ligands $\mathrm{L}^{\mathrm{L}} \mathrm{L}^{\mathrm{O}}$ and $\mathrm{L}^{\mathrm{O} 2}$}

The vast majority of bis(phosphine) ligands in the literature have chemically and magnetically identical phosphorus environments. The bis(phosphino)acenaphthene, L, represents a less common unsymmetrical bis(phosphine) ligand, and as such, values of $J_{\mathrm{PP}}$ coupling can be determined directly from its ${ }^{31} P\left\{{ }^{1} H\right\}$ NMR spectra. Despite the two $P$ atoms in $L$ being formally separated by four bonds, the compound displays ${ }^{4} J_{\mathrm{PP}}$ of $180 \mathrm{~Hz}$, which is observed as an $\mathrm{AB}$ spin system with $\delta_{\mathrm{P}}-11.3\left(\mathrm{Pr}_{2} \mathrm{P}\right)$ and -12.8 ppm $\left(\mathrm{Ph}_{2} \mathrm{P}\right)$ (Figure 3). The remarkably large magnitude of $J_{\mathrm{PP}}$ is attributed to the geometrically forced overlap of the two phosphorus lone pairs, resulting in a large through space coupling component. ${ }^{18,29,35}$ Upon oxidation of $\mathbf{L}$ to $\mathbf{L}^{\mathbf{0 2}}$, both phosphine lone pairs are sequestrated and the $J_{P P}$ coupling diminishes with two broad singlets observed for $\mathrm{L}^{\mathrm{O} 2}$ at $\delta_{\mathrm{P}} 54.7\left(\mathrm{Pr}_{2} \mathrm{P}(\mathrm{O})\right)$ and $31.4 \mathrm{ppm}\left(\mathrm{Ph}_{2} \mathrm{P}(\mathrm{O})\right)$. The monoxide, $\mathrm{L}^{\mathrm{O}}$, shows $J_{\mathrm{PP}}$ of $6.0 \mathrm{~Hz}$ with $\delta_{\mathrm{P}} 32.7\left(\mathrm{Ph}_{2} \mathrm{P}(\mathrm{O})\right)$ and $-7.2 \mathrm{ppm}\left(\mathrm{Pr}_{2} \mathrm{P}\right)$, indicating that even the sequestration of one lone pair results in a major decrease in the magnitude of $J_{\mathrm{PP}}$ (Figure 3). Similar observations were made for a related P $\cdots$..Se system; where upon selenation of the $\mathrm{P}(\mathrm{III})$ centre in $\mathrm{Ph}_{2} \mathrm{P}-\mathrm{Nap}-\mathrm{SePh}(\mathrm{Nap}=$ naphthalene-1,8-diyl) to $\mathrm{Ph}_{2} \mathrm{P}(=\mathrm{Se})$-Nap-SePh, the magnitude of ${ }^{4} J_{\mathrm{PSe}}$ decreased from $391 \mathrm{~Hz}$ to $24 \mathrm{~Hz} .{ }^{36}$ 


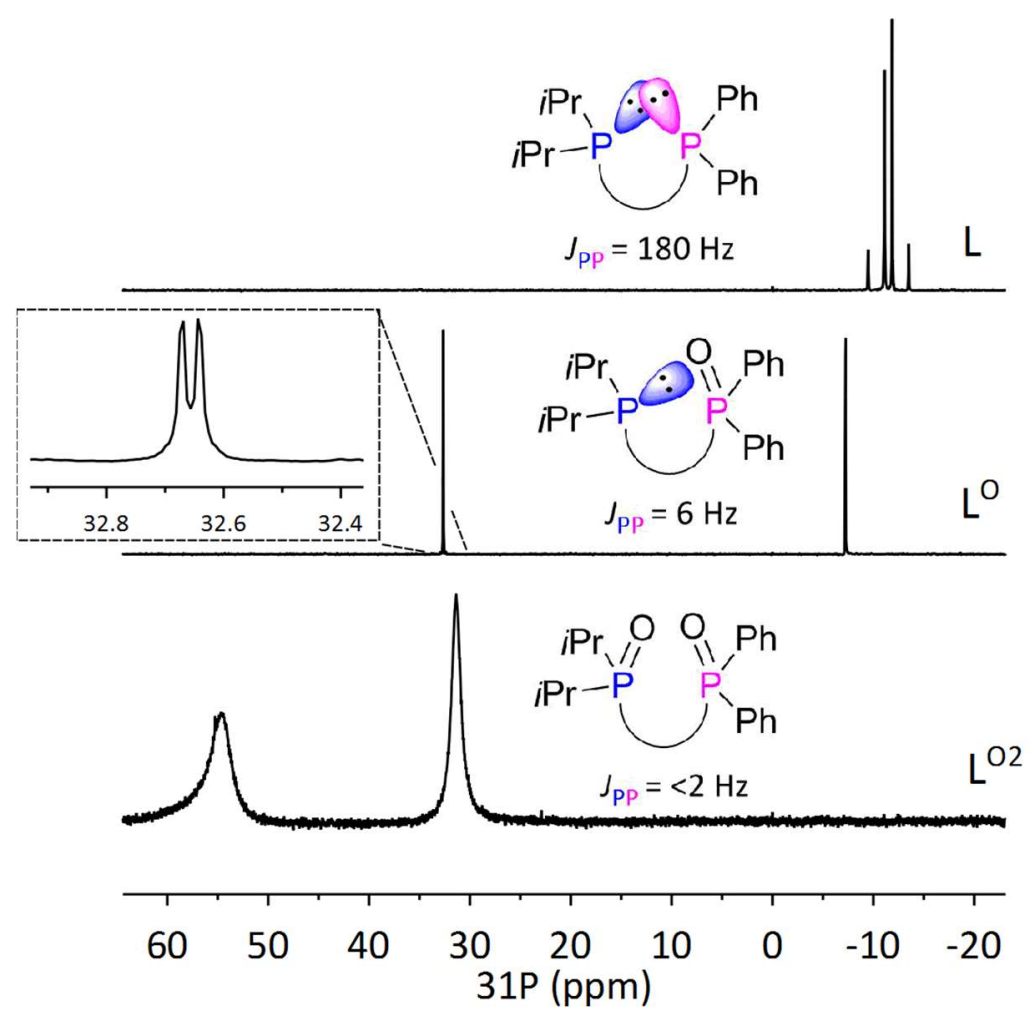

Figure 3: The ${ }^{31} \mathrm{P}\left\{{ }^{1} \mathrm{H}\right\}$ NMR spectra of $\mathrm{L}, \mathrm{L}^{\circ}$ and $\mathrm{L}^{02}$ recorded at $202.5 \mathrm{MHz}$ and schematic representations of the lone pair orbitals involved in the through-space $J_{P P}$ couplings.

\section{Group 12 [ $\left.\mathrm{LMCl}_{2}\right]$ Complexes ( $\mathrm{M}=\mathrm{Zn}, \mathrm{Cd}, \mathrm{Hg}$ )}

The ${ }^{31} \mathrm{P}\left\{{ }^{1} \mathrm{H}\right\}$ NMR spectrum of $\left[\mathrm{LZnCl}_{2}\right]$ shows two doublets at $\delta_{\mathrm{P}}-3.1\left(\mathrm{Pr}_{2} \mathrm{P}\right)$ and $-16.9 \mathrm{ppm}\left(\mathrm{Ph}_{2} \mathrm{P}\right)$ with a ${ }^{2} J_{\mathrm{PP}} 193.0 \mathrm{~Hz}$ (Table 1 and Figure 4). This indicates a slightly deshielded $i \mathrm{Pr}_{2} \mathrm{P}$ centre, and a slightly more shielded $\mathrm{PPh}_{2}$ centre compared to the free ligand $\mathbf{L}\left(\delta_{\mathrm{P}}-11.3\left(i \mathrm{Pr}_{2} \mathrm{P}\right)\right.$ and $\left.-12.8 \mathrm{ppm}(\mathrm{PhP})\right)$. In contrast, both phosphorus nuclei in $\left[\mathrm{LCdCl}_{2}\right]$ are deshielded vs. the free ligand $\mathbf{L}$, at $\delta_{\mathrm{P}} 13.2\left(\mathrm{Pr}_{2} \mathrm{P}\right)$ and $-6.6 \mathrm{ppm}$ $\left(\mathrm{Ph}_{2} \mathrm{P}\right)$. The deshielding effect is more pronounced in $\left[\mathrm{LHgCl}_{2}\right]$ with the two doublets at $\delta_{\mathrm{P}} 47.7\left(\mathrm{Pr}_{2} \mathrm{P}\right)$ and $19.8 \mathrm{ppm}\left(\mathrm{Ph}_{2} \mathrm{P}\right)$. 
Table 1: Chemical shifts $\delta_{p}(p p m)$ and $J$ couplings $(H z)$ in free ligands and [ $\left.L M X_{2}\right]$ complexes $(M=Z n, C d$, $\mathrm{Hg}, \mathrm{Ni}, \mathrm{Pd}, \mathrm{Pt} ; \mathrm{X}=\mathrm{Cl}, \mathrm{Br}$ ).

\begin{tabular}{|c|c|c|c|c|c|c|}
\hline & $\begin{array}{l}\text { Metal } \\
\text { geometry }\end{array}$ & $\delta_{\mathrm{P}} i \mathrm{Pr}_{2} \mathrm{P}$ & $\delta_{\mathrm{P}} \mathrm{Ph}_{2} \mathrm{P}$ & $J_{\mathrm{PP}}$ & ${ }^{1} J_{P(\text { (iPr2)-M }}$ & ${ }^{1} J_{P(P h 2)-M}$ \\
\hline $\mathrm{L}^{[\mathrm{a}]}$ & - & -11.3 & -12.8 & 180.0 & - & - \\
\hline $\mathbf{L}^{0}$ & - & -7.2 & 32.7 & 6.0 & - & - \\
\hline$L^{02}$ & - & 32.7 & 31.4 & 0 & - & - \\
\hline$\left[\mathrm{LZnCl}_{2}\right]$ & tetrahedral & -3.1 & -16.9 & 193.0 & - & - \\
\hline$\left[\mathrm{LCdCl}_{2}\right]$ & tetrahedral & 13.2 & -6.6 & 231.5 & $1156.7 / 1106.0^{[b]}$ & $1025.0 / 979.5^{[b]}$ \\
\hline$\left[\mathrm{LHgCl}_{2}\right]$ & tetrahedral & 47.7 & 19.8 & 309.1 & 3655.1 & 2336.9 \\
\hline$\left[\mathrm{LNiCl}_{2}\right]^{[\mathrm{c}]}$ & sq. planar & 27.1 & 14.3 & 116.6 & - & - \\
\hline$\left[\mathrm{LPdBr}_{2}\right]$ & sq. planar & 35.1 & 18.5 & 16.0 & - & - \\
\hline$\left[\mathrm{LPtCl}_{2}\right]$ & sq. planar & 13.4 & -2.3 & 26.1 & 3351.9 & 3407.3 \\
\hline$\left[\mathrm{LMo}(\mathrm{CO})_{4}\right]^{[\mathrm{a}]}$ & octahedral & 43.1 & 34.5 & 33.5 & - & - \\
\hline
\end{tabular}

${ }^{[a]}$ ref ${ }^{18} \cdot{ }^{[b]}$ Values for ${ }^{113} \mathrm{Cd}$ and ${ }^{111} \mathrm{Cd}$ isotopologues. ${ }^{[c]} \mathrm{NMR}$ spectra acquired at $193 \mathrm{~K}$.

The most distinct feature in this series is the increase in the magnitude of ${ }^{2} J_{\mathrm{PP}}$ as the atomic number of the metal atom increases, with a ${ }^{2} J_{\mathrm{PP}}$ of $193.0 \mathrm{~Hz}$ in $\left[\mathbf{L Z n C l}_{2}\right] ; 231.5 \mathrm{~Hz}$ in $\left[\mathbf{L C d C l}_{2}\right]$ and $309.1 \mathrm{~Hz}$ in [ $\left.\mathbf{L H g C l}_{2}\right]$. Notably, magnitudes of these couplings are not vastly different to that observed in the free ligand L, where the $J_{\mathrm{PP}}$ of $180 \mathrm{~Hz}$ is comprised exclusively of the through-space component. It is believed that upon coordination to the metal centre, the coupling becomes metal-mediated; the change in magnitude of $J_{\mathrm{PP}}$ is attributed to the increasing ability of the metal $(\mathrm{Zn}<\mathrm{Cd}<\mathrm{Hg})$ to transfer magnetic spin information between the two phosphorus donor atoms.

Well resolved satellite peaks were observed in the ${ }^{31} \mathrm{P}\left\{{ }^{1} \mathrm{H}\right\}$ NMR spectra for both ${ }^{111} \mathrm{Cd}$ and ${ }^{113} \mathrm{Cd}$ isotopologues in $\left[\mathrm{LCdCl}_{2}\right]$, as well as for the ${ }^{199} \mathrm{Hg}$ isotopologue in $\left[\mathrm{LHgCl}_{2}\right]$ (Figure 4). Observed $J_{\mathrm{PCd}}$ and $J_{\mathrm{PHg}}$ couplings are directly linked to the $\sigma$-donor strength of the phosphine, with the more basic phosphine $\left(i \mathrm{Pr}_{2} \mathrm{P}\right)$ having a larger coupling to the metal centre (Table 1). This is as expected for the group 12 metals in +2 oxidation state. ${ }^{37-38}$ Interestingly, the electronic properties and sterically fixed nature of the ligand $\mathbf{L}$, in which the two donor atoms are held in close proximity, results in smaller magnitudes of ${ }^{1} J_{\mathrm{PM}}$ compared to the related complexes of (less rigid and less compact ligand) dippf (dipff $=1,1^{\prime}$ bis(diisopropylphosphino)ferrocene). ${ }^{39}$ These displayed ${ }^{1} J_{\mathrm{P} 111 \mathrm{Cd}}=1390$ and ${ }^{1} J_{\mathrm{P} 113 \mathrm{Cd}}=1450 \mathrm{~Hz}$ in $\left[\mathrm{CdCl}_{2}\right.$ (dipff)] and ${ }^{1} J_{\mathrm{PHg}}=4190 \mathrm{~Hz}$ in $\left[\mathrm{HgCl}_{2}\right.$ (dipff)]. 


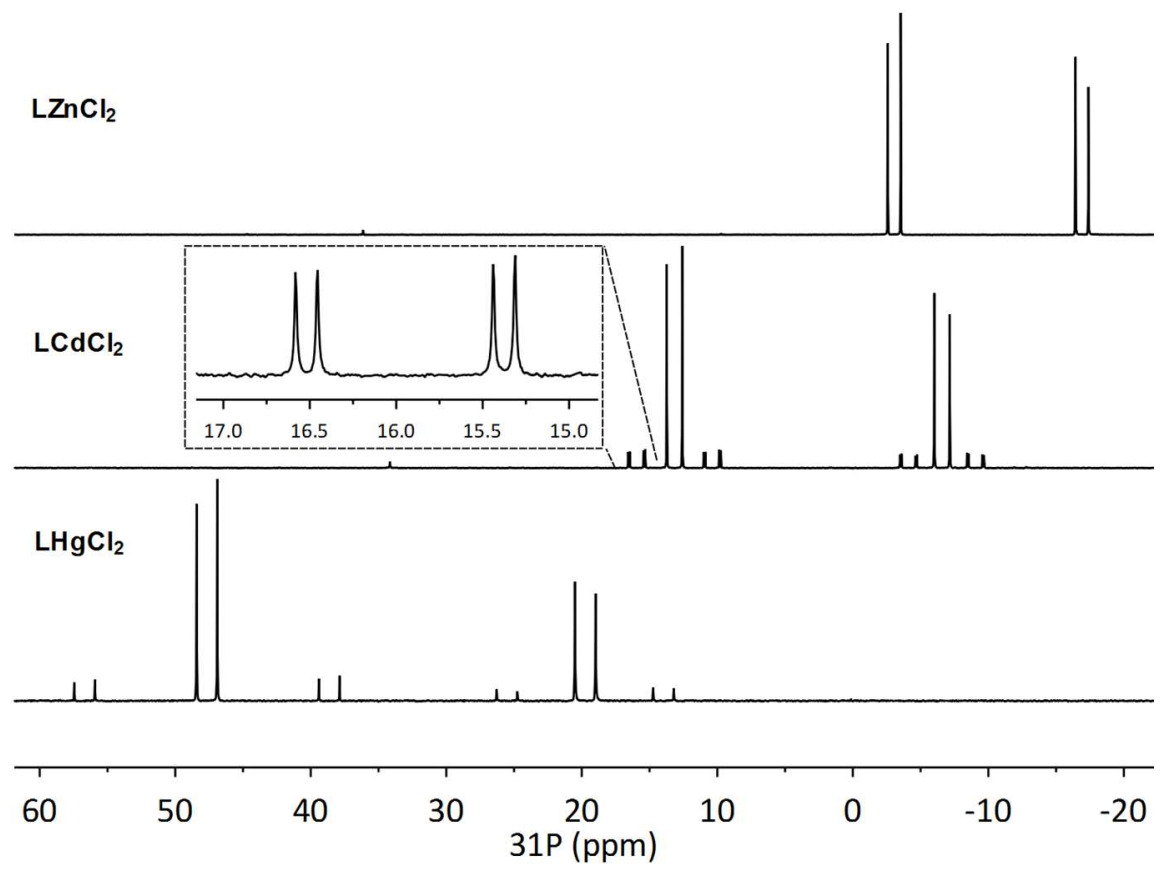

Figure 4: Stacked ${ }^{31} \mathrm{P}\left\{{ }^{1} \mathrm{H}\right\} \mathrm{NMR}$ spectra of $\left[\mathrm{LMCl}_{2}\right](\mathrm{M}=\mathrm{Zn}, \mathrm{Cd}, \mathrm{Hg})$ recorded at $202.5 \mathrm{MHz}$ with the $\mathrm{Cd}$ satellites expansion shown.

We conclude that the $J_{P p}$ increases with increasing size of the metal atom, in the series of $\left[\mathrm{LZnCl}_{2}\right]$, [ $\left.\mathrm{LCdCl}_{2}\right]$ and $\left[\mathrm{LHgCl}_{2}\right]$, although the change is not dramatic. It appears that the through-space coupling component is not a major contributor in these complexes, in comparison to the through-bond coupling, as this would be expected to lead to smaller $J_{\mathrm{PP}}$ magnitudes as the metal size (and hence P...P separation) increases.

\section{Group 10 [LMX $]$ Complexes ( $\mathrm{M}=\mathrm{Ni}, \mathrm{Pd}, \mathrm{Pt})$}

The ${ }^{31} \mathrm{P}\left\{{ }^{1} \mathrm{H}\right\}$ NMR spectra of $\left[\mathrm{LPdBr}_{2}\right]$ and $\left[\mathrm{LPtCl}_{2}\right]$ indicate a substantial deshielding of the phosphorus atoms upon coordination to the Group 10 metal centres (Table 1). There is also a dramatic decrease in the magnitudes of ${ }^{2} J_{\mathrm{Pp}}$ when comparing the Group 10 cis-square planar complexes $(\mathrm{Pd}, \mathrm{Pt})$ with group 12 tetrahedral complexes $(\mathrm{Zn}, \mathrm{Cd}, \mathrm{Hg})$ discussed above. The magnitude of $J_{\mathrm{pp}}$ increases slightly with increasing metal mass $\left({ }^{2} J_{\mathrm{PP}} 16.0\right.$ and $26.1 \mathrm{~Hz}$, respectively, for [ $\left.\mathrm{LPdBr}_{2}\right]$ and $\left.\left[\mathrm{LPtCl}_{2}\right]\right)$, however both metal and halide ligands are different in this series and hence the observed change cannot be attributed solely to the metal atom. This is because ${ }^{1} J_{\mathrm{MP}}$ are significantly dependent not only on the nature of the metal, but to a significant degree also on the ligand trans to the phosphorus atom. For completeness it is of interest to mention relevant NMR data of an octahedral molybdenum complex, $\left[\mathrm{LMo}(\mathrm{CO})_{4}\right]$, which have been reported by us earlier. ${ }^{18}$ In this complex, ${ }^{2} J_{\mathrm{PP}}$ of $33.5 \mathrm{~Hz}$ was observed, which is clearly more in line with that observed for square planar, rather than tetrahedral complexes of L (Table 1). 
Since partially filled $d$-orbitals ( $d^{8}$ metal configuration) are present in the Group 10 complexes, the $\pi$ back-bonding contribution is likely to be significant. ${ }^{40}$ This affects the ${ }^{1} \mathrm{JPt}_{\mathrm{PPt}}$ magnitudes in $\left[\mathrm{LPtCl}_{2}\right]$, in which the stronger $\sigma$-donating phosphine, the $\operatorname{Pr}_{2} \mathrm{P}$ group, displays a slightly smaller ${ }^{1} J_{\mathrm{PPt}}$ magnitude than the less basic $\mathrm{Ph}_{2} \mathrm{P}$ group. This is the opposite trend to that observed with $\left[\mathrm{LCdCl}_{2}\right]$ and $\left[\mathrm{LHgCl}_{2}\right]$. The coupling constants were obtained from ${ }^{195} \mathrm{Pt}$ satellites in the ${ }^{31} \mathrm{P}\left\{{ }^{1} \mathrm{H}\right\}$ NMR spectra shown in Table 1 and Figure 5. The ${ }^{195} \mathrm{Pt}\left\{{ }^{1} \mathrm{H}\right\}$ NMR spectrum complements this with a doublet of doublets centred at $\delta_{\mathrm{Pt}}-$ $4504.1 \mathrm{ppm}$, confirming the magnitudes of ${ }^{1} \mathrm{~J}_{\mathrm{ptP}} 3407.3$ and $3351.9 \mathrm{~Hz}$.
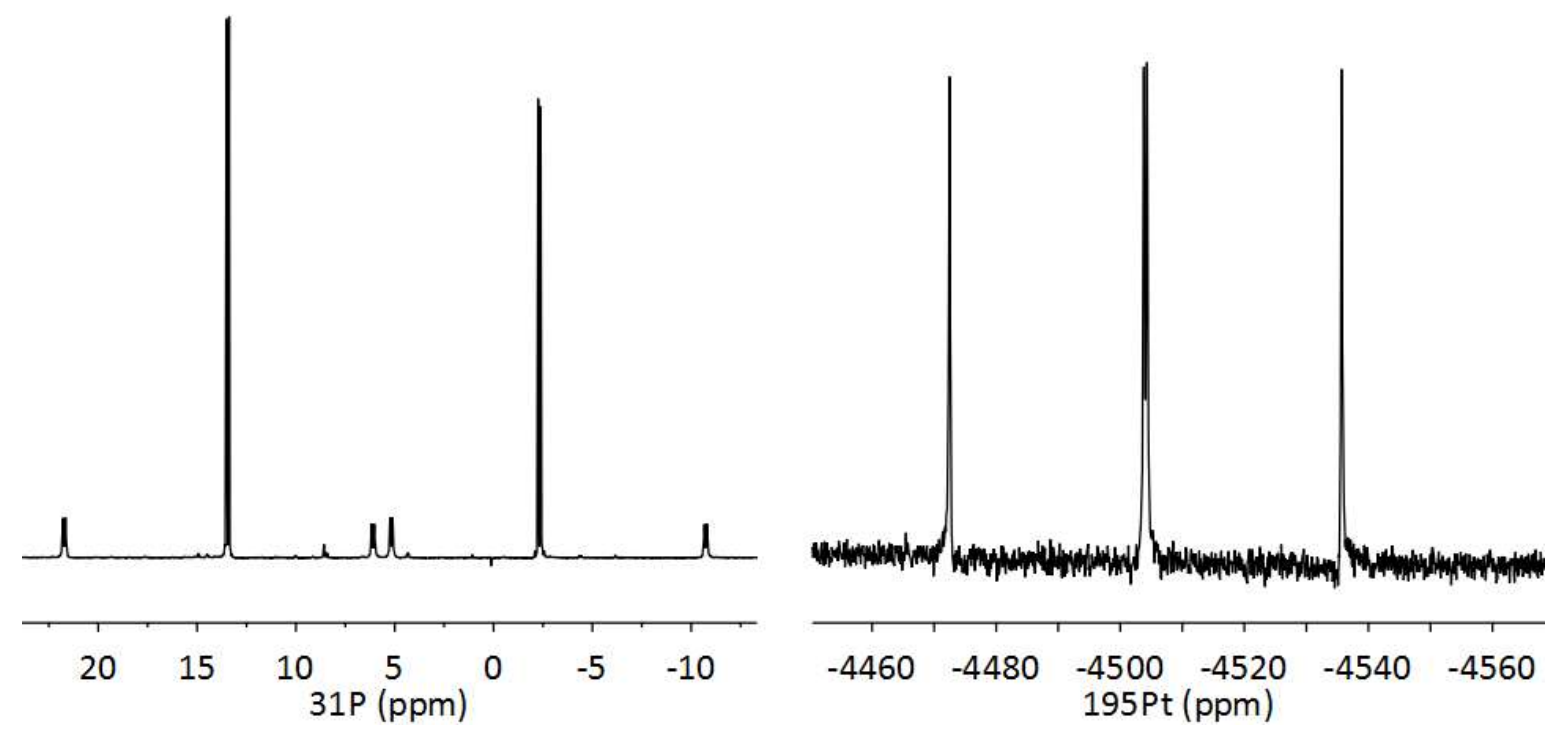

Figure 5: NMR spectra of [ $\left.\mathrm{LPtCl}_{2}\right]$. Left: ${ }^{31} \mathrm{P}\left\{{ }^{1} \mathrm{H}\right\}$ NMR spectrum $(202.5 \mathrm{MHz})$. Right: ${ }^{195} \mathrm{Pt}\left\{{ }^{1} \mathrm{H}\right\} \mathrm{NMR}$ spectrum $(107.0 \mathrm{MHz})$.

Rather peculiarly, at ambient conditions, the ${ }^{1} \mathrm{H}$ NMR spectrum of $\left[\mathrm{LNiCl}_{2}\right]$ was entirely devoid of any $J_{\mathrm{HP}}$ couplings, in contrast to the ${ }^{1} \mathrm{H}$ NMR spectra of $\left[\mathbf{L P d C l}_{2}\right]$ and $\left[\mathrm{LPtCl}_{2}\right]$, which clearly showed the ${ }^{2} J_{\mathrm{HP}}$ and ${ }^{3} J_{\mathrm{HP}}$ couplings in the isopropyl groups. In addition, no signal was detected in the ${ }^{31} \mathrm{P}\left\{{ }^{1} \mathrm{H}\right\} \mathrm{NMR}$ spectrum of [ $\left[\mathrm{LiCl}_{2}\right]$ at $298 \mathrm{~K}$. Upon cooling a solution of $\left[\mathbf{L N i C l}_{2}\right]$ to $193 \mathrm{~K}$, two well resolved doublets $\left(w_{1 / 2}=5 \mathrm{~Hz}\right)$ were observed at $\delta_{\mathrm{p}} 27.1$ and $14.3 \mathrm{ppm}$ with ${ }^{2} J_{\mathrm{PP}}$ of $116.6 \mathrm{~Hz}$ (Figure 6). Upon increasing the temperature, the two doublets observed in the ${ }^{31} \mathrm{P}\left\{{ }^{1} \mathrm{H}\right\}$ NMR spectra broaden, reaching $w_{1 / 2}$ of $c a .265 \mathrm{~Hz}$ at $233 \mathrm{~K}$. Upon increasing temperature to $248 \mathrm{~K}$ and above, no signal is detected, and no new signal emerges even at $293 \mathrm{~K}$. A plausible explanation for this broadening appeared to be paramagnetism of [ $\left.\mathbf{L N i C l}_{2}\right]$, which would be expected if the $d^{8}$ nickel(II) centre adopted a tetrahedral geometry. In direct contradiction with this, the magnetic susceptibility $\left(\mu_{\text {eff }}\right)$ of the solid $\left[\mathrm{LNiCl}_{2}\right]$ was found to be very low, at 0.1-0.2 BM (at 294 $\mathrm{K})$, instead of the expected value of around 2.9-3.2 BM, typical for tetrahedral nickel(II) species. ${ }^{41}$

However, this phenomenon is not unknown with nickel(II) complexes with strong field ligands, such as phosphines or amines. A comprehensive study of magnetism in bis(phosphine) nickel(II) complexes, such as [(dtbpe)NiX $\mathrm{N}_{2}$ (dtbpe $=1,2$-bis(di-tert-butylphosphanyl)ethane), was recently carried 
out by Schultz, ${ }^{42}$ who concluded that an equilibrium between planar (singlet) and pseudo-tetrahedral (triplet) complexes is likely responsible for magnetic properties similar to those observed by us in [ $\mathbf{L N i C l}_{2}$ ]. Similar conclusions were made by Hierso for tetraphosphine ferrocenyl $\mathrm{NiCl}_{2}$ complex, where the apparent paramagnetism was rationalised by the fluxional behaviour of the $\mathrm{Ni}(\mathrm{II})$ centre leading to an average spectrum between a diamagnetic square-planar complex and a paramagnetic tetrahedral complex. ${ }^{28}$ A plausible mechanism of fluxionality around $\mathrm{Ni}(\mathrm{II})$ centre in $\left[\mathrm{LNiCl}_{2}\right]$ includes an inversion process with respect to the rigid bis(phosphine) acenaphthene backbone, as shown in Figure 7.

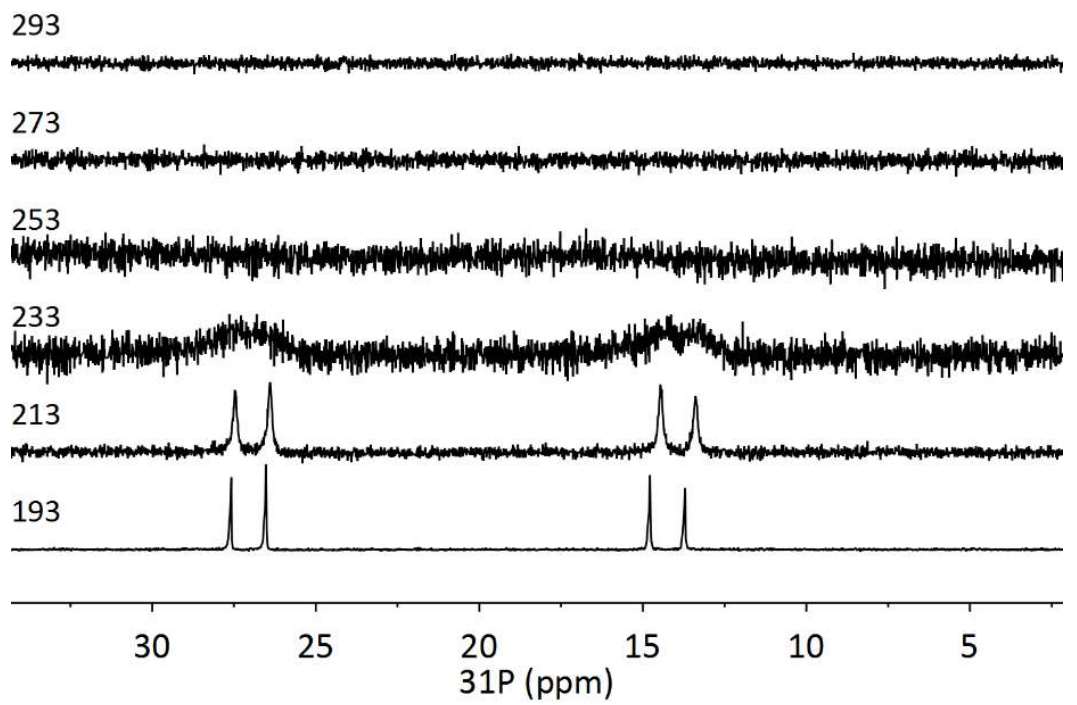

Figure 6: The ${ }^{31} \mathrm{P}\left\{{ }^{1} \mathrm{H}\right\}$ VT NMR of $\left[\mathrm{LNiCl}_{2}\right]$ recorded in $\mathrm{CD}_{2} \mathrm{Cl}_{2}$ at $109.4 \mathrm{MHz}$. Temperature is in Kelvin.

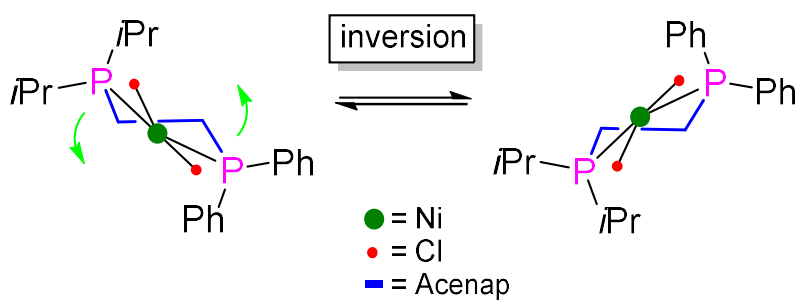

Figure 7: Plausible inversion of [ $\mathrm{LNiCl}_{2}$ ] leading to an equilibrium between planar (singlet) and pseudotetrahedral (triplet) geometry, giving rise to the paramagnetism. The molecule is viewed along the acenaphthene plane.

\section{Group 11 Complexes $\left[\mathrm{L}_{2} \mathrm{Ag}\right] \mathrm{SbF}_{6}$ and $\left[(\mathrm{LCuCl})_{2}\right]$}

The reaction of $\mathbf{L}$ with half an equivalent of silver hexafluoroantimonate gave $\left[\mathbf{L}_{2} \mathbf{A g}\right] \mathbf{S b F}_{6}$ as an air stable, light sensitive microcrystalline solid. Silver has two naturally abundant isotopes, ${ }^{107} \mathrm{Ag}$ and ${ }^{109} \mathrm{Ag}(51.8 \%$ 
and $48.2 \%$ abundance, respectively), both of which are NMR active $(I=1 / 2)$. This leads to a complex ${ }^{31} \mathrm{P}\left\{{ }^{1} \mathrm{H}\right\}$ NMR spectrum, which represents an $A^{\prime} A^{\prime} B B^{\prime} X X^{\prime}$ spin system, in which $X$ and $X^{\prime}$ are the two NMR active isotopes of silver $\left(X={ }^{107} \mathrm{Ag} ; X^{\prime}={ }^{109} \mathrm{Ag}\right.$, respectively). $A$ and $A^{\prime}$ represent phosphorus atoms in $\operatorname{Pr}_{2} P$ group, whilst $B$ and $B^{\prime}$ represent phosphorus atoms in $\mathrm{Ph}_{2} \mathrm{P}$ group. An iterative spin system simulation was performed to elucidate the relevant coupling constants (Figure 8).

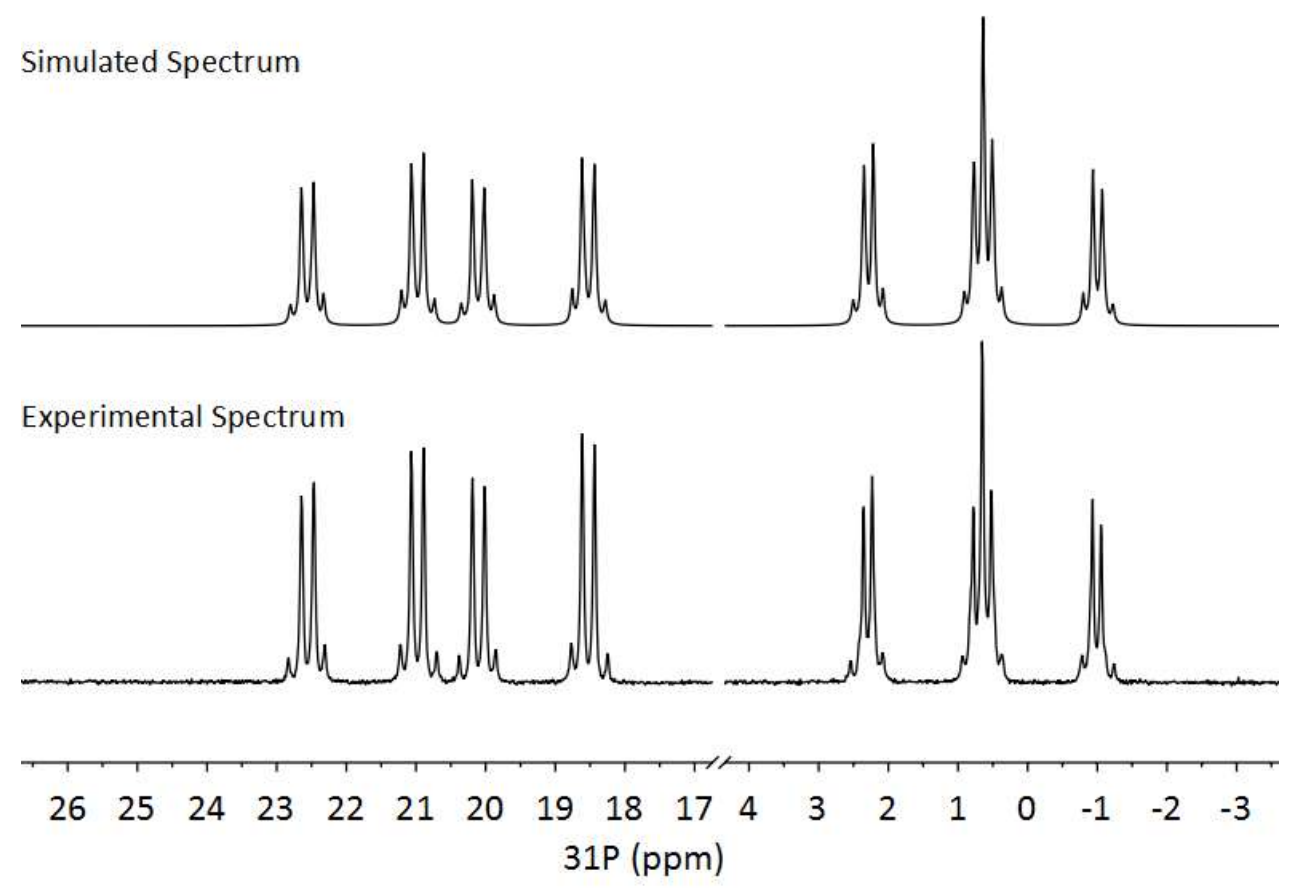

Figure 8: The experimental ${ }^{31} \mathrm{P}\left\{{ }^{1} \mathrm{H}\right\} \mathrm{NMR}$ spectrum of $\left[\mathrm{L}_{2} \mathbf{A g}\right] \mathrm{SbF}_{6}$ acquired at $109.4 \mathrm{MHz}$ (bottom) and simulated spectrum (top).

The series of signals at $c a \delta_{\mathrm{P}} 23$ to $18 \mathrm{ppm}$ corresponds to the $\mathrm{Pr}_{2} \mathrm{P}$ group and the set of peaks ranging from $\delta_{\mathrm{P}} 3$ to $-1 \mathrm{ppm}$ corresponds to the $\mathrm{Ph}_{2} \mathrm{P}$ group. The coupling constants which can be read directly from the spectrum are the ${ }^{2} J_{\mathrm{PP}}(171.5 \mathrm{~Hz})$ and the ${ }^{1} J_{\mathrm{PAg}}$ (of which there are 4). All other couplings (of which there are also 4) were obtained from iterative fitting (Figure 9). 


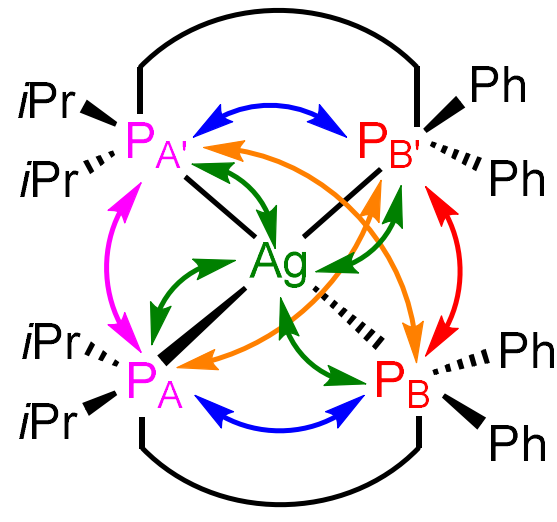

$$
\begin{aligned}
& { }^{2} J_{A B}=171.5 \mathrm{~Hz} \quad{ }^{1} J_{A X}=249.1 \mathrm{~Hz} \\
& { }^{2} J_{A^{\prime} B^{\prime}}=171.5 \mathrm{~Hz}{ }^{1} \int_{A X^{\prime}}=287.5 \mathrm{~Hz} \\
& { }^{2} J_{A A^{\prime}}=17.2 \mathrm{~Hz} \quad{ }^{1} J_{B X}=172.9 \mathrm{~Hz} \\
& { }^{2} \mathrm{~J}_{\mathrm{BB}^{\prime}}=16.3 \mathrm{~Hz} \quad{ }^{1} \mathrm{~J}_{\mathrm{BX}^{\prime}}=200.6 \mathrm{~Hz} \\
& { }^{2} J_{A^{\prime} B}=0.9 \mathrm{~Hz} \quad A=A^{\prime}={ }^{31} P \\
& { }^{2} \int_{A B^{\prime}}=0.9 \mathrm{~Hz} \\
& B=B^{\prime}={ }^{31} P \\
& X={ }^{107} \mathrm{Ag} \\
& X^{\prime}={ }^{109} \mathrm{Ag}
\end{aligned}
$$

Figure 9: Diagram of the spin-spin couplings in $\left[\mathrm{L}_{2} \mathbf{A g}\right] \mathrm{SbF}_{6}$.

The ${ }^{2} J_{P P}\left({ }^{2} J_{A B}\right.$ and $\left.{ }^{2} J_{A^{\prime} B^{\prime}}\right)$ coupling of $171.5 \mathrm{~Hz}$ is rather comparable to that in the free ligand $\mathbf{L}(180.0 \mathrm{~Hz})$, indicating that silver is an effective mediator of spin information between the two phosphines. The magnitudes of ${ }^{1} J_{\mathrm{PAg}}$ are directly proportional to basicity of the phosphine ligands $\left({ }^{1} /\left({ }^{31} \mathrm{P}_{\mathrm{A}}-{ }^{109} \mathrm{Ag}\right) 287.5 \mathrm{~Hz}\right.$, $\left.{ }^{1} J\left({ }^{31} \mathrm{P}_{\mathrm{B}}-{ }^{109} \mathrm{Ag}\right) 200.6 \mathrm{~Hz}, \mathrm{P}_{\mathrm{A}}=i \mathrm{Pr}_{2} \mathrm{P} ; \mathrm{P}_{\mathrm{B}}=\mathrm{Ph}{ }_{2} \mathrm{P}\right)$. The corresponding ${ }^{107} \mathrm{Ag}$ couplings $\left({ }^{1} J\left({ }^{31} \mathrm{P}_{\mathrm{A}}-{ }^{107} \mathrm{Ag}\right)\right.$ of 249.1 $\mathrm{Hz}$ and ${ }^{1} \mathrm{~J}\left({ }^{31} \mathrm{P}_{\mathrm{B}}-{ }^{107} \mathrm{Ag}\right)$ of $\left.172.9 \mathrm{~Hz}\right)$ are consistent with the ratio of the gyromagnetic ratios of ${ }^{107} \mathrm{Ag}:{ }^{109} \mathrm{Ag}$ (ca. $1: 1.15)$.

Cuprous chloride and $\mathbf{L}$ reacted in a 1:1 ratio to produce the only dinuclear species in this study, [(LCuCl $\left.)_{2}\right]$. The ${ }^{31} \mathrm{P}\left\{{ }^{1} \mathrm{H}\right\}$ NMR spectrum of $\left[\left(\mathrm{LCUCl}_{2}\right]\right.$ at $298 \mathrm{~K}$ is broadened $\left(w_{1 / 2} \mathrm{Ca} .45 \mathrm{~Hz}\right)$. Despite this, a ${ }^{2} J_{\mathrm{PP}}$ of $215 \mathrm{~Hz}$ can be read from the spectrum; this is again rather comparable to that in free ligand $\mathbf{L}(180.0$ $\mathrm{Hz})$.

\section{Cobalt(II) and Copper(II) Complexes of $\mathrm{L} \mathrm{L}^{\circ}$ and $\mathrm{L}^{\mathrm{O2}}$}

As the cobalt(II) complexes $\left[\mathrm{LCoCl}_{2}\right],\left[\mathrm{L}^{\circ} \mathrm{CoCl}_{2}\right]$ and $\left[\mathrm{L}^{02} \mathrm{CoCl}_{2}\right]$ are paramagnetic ( $d^{7}$ configuration), their NMR spectra are extremely broad and no information on $J_{\mathrm{PP}}$ can be extracted. The same applies to the $\mathrm{Cu}(\mathrm{II})$ complex $\left[\mathrm{L}^{\mathrm{O}} \mathrm{CuCl}_{2}\right]$ ( $d^{9}$ configuration).

\section{Structural Investigations}

\section{The ligands ( $L, L^{0}$ and $\left.L^{02}\right)$}

Crystal structures of $\mathbf{L}, \mathbf{L}^{0}$ and $\mathbf{L}^{\mathbf{0 2}}$ are shown in Figure 10 and crystallographic information is presented in Table 2. Despite the two rather bulky phosphine groups being attached in the peri-positions, only moderate in-plane and out-of-plane distortion is observed in L. The largest displacement from the acenaphthene mean plane $(0.233(1) \AA)$ is shown by the phosphorus atom of $\mathrm{PiPr}_{2}$ group. Nevertheless, 
the constraints of the acenaphthene backbone result in a forced overlap of the two lone pairs on phosphorus atoms. The dominant repulsive interaction is partially counterbalanced by a weak attractive interaction in which some of the electron density from the lone pair of the $i \mathrm{Pr}_{2} \mathrm{P}$ phosphorus atom is transferred into one of the $\sigma^{*}\left(\mathrm{P}-\mathrm{C}_{\text {ipso }}\right)$ orbitals of the $\mathrm{Ph}_{2} \mathrm{P}$ group. This weak bonding interaction results in a quasi-linear $\left(\mathrm{Pr}_{2}\right) \mathrm{P} \ldots \mathrm{P}-\mathrm{C}_{\text {ipso }}$ arrangement $\left(\mathrm{Pg} \ldots \mathrm{P} 1-\mathrm{C} 13 \mathrm{175.6}(2)^{\circ}\right)$ in the crystal structure (Figure 10). This interaction may facilitate transfer of spin information between the two phosphorus atoms, contributing to the rather large magnitude of $J_{\mathrm{PP}}$ of $180 \mathrm{~Hz}$ observed for $\mathrm{L}$. The resulting $\mathrm{P}$...P distance of $3.100(2)$ Å represents $80 \%$ of the sum of Van der Waals radii. ${ }^{3}$
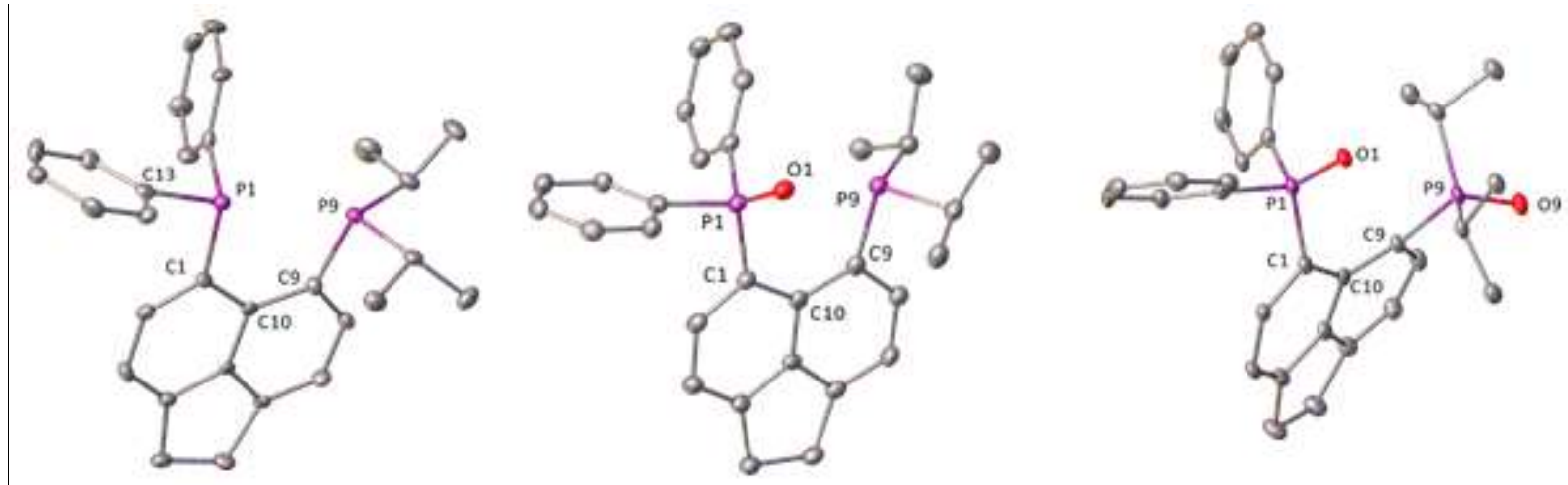

Figure 10: The crystal structures of $\mathbf{L}, \mathbf{L}^{\mathbf{0}}$ and $\mathbf{L}^{\mathbf{0 2}}$. Hydrogen atoms and solvating molecules are omitted. Thermal ellipsoids are plotted at the $40 \%$ probability level.

The addition of one oxygen atom in $\mathbf{L}^{\circ}$ does not have a dramatic influence on the structural features of the peri-region (Figure 10). The P...P distance does increase marginally to 3.308(1) $\AA$, but the changes in other structural parameters are small, such as the change of P9-C9...C1-P1 dihedral angle from $6.1(2)^{\circ}$ in $\mathbf{L}$ to $4.7(2)^{\circ}$ in $\mathbf{L}^{\circ}$ (see Table 2 ).

The oxidation of both $\mathrm{P}(\mathrm{III})$ centres to $\mathrm{P}(\mathrm{V})$ in $\mathrm{L}^{02}$ results in dramatic structural changes in the periregion. The P...P distance shows a large increase to 3.846(2) $\AA$. The out-of-plane displacements of the phosphorus atoms ( $c a .1 \AA$ ) and the large P1-C1 ‥C9-P9 dihedral angle of $46.2(2)^{\circ}$ reflect the increased steric congestion and repulsive interactions between the two phosphine oxide groups. These features are akin to the bis(phosphine)sulfide, $\operatorname{Pr}_{2} \mathrm{P}(\mathrm{S})$-Ace- $\mathrm{P}(\mathrm{S}) \mathrm{Ph}_{2}$, reported previously, ${ }_{18}$ although as expected, the distortions are even more pronounced in the bis(sulfide) compared to the bis(oxide) $\mathbf{L}^{\mathbf{0 2}}$. 
Table 2: Selected bond distances $(\AA)$ and angles $\left(^{\circ}\right)$ for ligands, $\mathbf{L}, \mathbf{L}^{\mathbf{O}}$ and $\mathbf{L}^{\mathbf{0 2}}$. Numbering scheme is shown in Figure 10.

\begin{tabular}{|c|c|c|c|}
\hline Compound & $\mathbf{L}^{[\mathrm{a}]}$ & $\mathrm{L}^{\circ} \cdot \mathrm{MeOH}$ & $\mathrm{L}^{\mathrm{O}} \cdot \mathrm{CH}_{2} \mathrm{Cl}_{2}$ \\
\hline \multicolumn{4}{|c|}{ peri-region bond distances } \\
\hline P1 $\cdots$ P9 & $3.100(2)$ & $3.308(1)$ & $3.846(2)$ \\
\hline $\mathrm{P}-\mathrm{O}$ & - & $1.494(2)$ & $1.504(3), 1.486(3)$ \\
\hline \multicolumn{4}{|c|}{ peri-region bond angles } \\
\hline P1-01 ...P9 & - & $80.78(9)$ & $94.2(1)$ \\
\hline $\mathrm{P} 9 \ldots \mathrm{P} 1-\mathrm{C}_{\text {ipso }}$ & $175.6(2)$ & $173.8(1)$ & $167.7(1)$ \\
\hline splay angle $^{[b]}$ & $14(1)$ & $21.0(8)$ & $25(1)$ \\
\hline \multicolumn{4}{|c|}{ out-of-plane displacement ${ }^{[\mathrm{c}]}$} \\
\hline P1 & 0.053 & 0.099 & 0.962 \\
\hline P9 & -0.233 & -0.110 & -0.911 \\
\hline \multicolumn{4}{|c|}{ peri-region torsion angle } \\
\hline P9-C9...C1-P1 & $6.1(2)$ & $4.7(2)$ & $46.2(2)$ \\
\hline
\end{tabular}

\section{Group 12 and 10 [LMX $\mathrm{LM}_{2}$ Complexes ( $\mathrm{M}=\mathrm{Zn}, \mathrm{Cd}, \mathrm{Hg}, \mathrm{Ni}, \mathrm{Pd}, \mathrm{Pt}, \mathrm{X}=\mathrm{Cl}, \mathrm{Br}$ )}

The metal atoms in Group 12 complexes [ $\left.\mathrm{LMCl}_{2}\right](\mathrm{M}=\mathrm{Zn}, \mathrm{Cd}, \mathrm{Hg})$ adopt a distorted tetrahedral geometry with $\mathrm{P} 1-\mathrm{M}-\mathrm{P9}$ angles being rather compressed, ranging from $86.41(3)^{\circ}$ to $93.47(3)^{\circ}$ (Figure 11 ). Despite the compressed P1-M-P9 angles, the P1 ...P9 distance in these complexes is elongated by ca. 0.4 to $0.5 \AA$ compared to the free ligand $\mathbf{L}$, and this distance increase marginally with the atomic number of the metal (the order is $\mathrm{L}<\mathrm{Zn}<\mathrm{Cd}<\mathrm{Hg}$ ) (Table 3).

The group 12 series shows large distortions of the acenaphthene peri-region due to the competing requirements of the ideal (tetrahedral) ligand sphere geometry and the (rigid) acenaphthene backbone (Table 3). The phosphorus atoms are significantly displaced above and below the mean acenaphthene plane (displacements ranging from 0.5 to $0.8 \AA$ ), resulting in the P9-C9...C1-P1 dihedral angles of 29 to $34^{\circ}$. Also in-plane distortions are increased in this series with splay angles of around $21^{\circ}$ (c.f. $14^{\circ}$ in $\left.\mathrm{L}\right)$.

The metal atoms in Group 10 complexes [ $\left.\mathbf{L N i C l}_{2}\right],\left[\mathrm{LPdBr}_{2}\right]$ and $\left[\mathrm{LPtCl}_{2}\right]$ adopt a distorted square planar geometry (Figure 11). In contrast to tetrahedral complexes [ $\left.\mathrm{LMCl}_{2}\right](\mathrm{M}=\mathrm{Zn}, \mathrm{Cd}, \mathrm{Hg})$, the square planar coordination of $\mathbf{L}$ to the metal atoms $\mathrm{Ni}, \mathrm{Pd}$ and $\mathrm{Pt}$ results in a very modest increase in the P...P distances by only 0.03 to $0.11 \AA$ compare to free ligand $\mathbf{L}$ (Table 3 ). The splay angle values are either marginally smaller or identical for Group 10 metal complexes and free ligand $\mathbf{L}$. On the other hand, the out-of-plane distortions are slightly increased in these complexes compare to the free ligand $\mathbf{L}$, with the 
largest displacement of $0.79 \AA$ for $\mathrm{P} 1$ in [ $\left.\mathrm{LPdBr}_{2}\right]$. In line with this, the P9-C9...C1-P1 dihedral angles are increased (ranging from ca. 29 to $37^{\circ}$ ) compared to the free ligand $\mathbf{L}\left(c a .6^{\circ}\right)$.
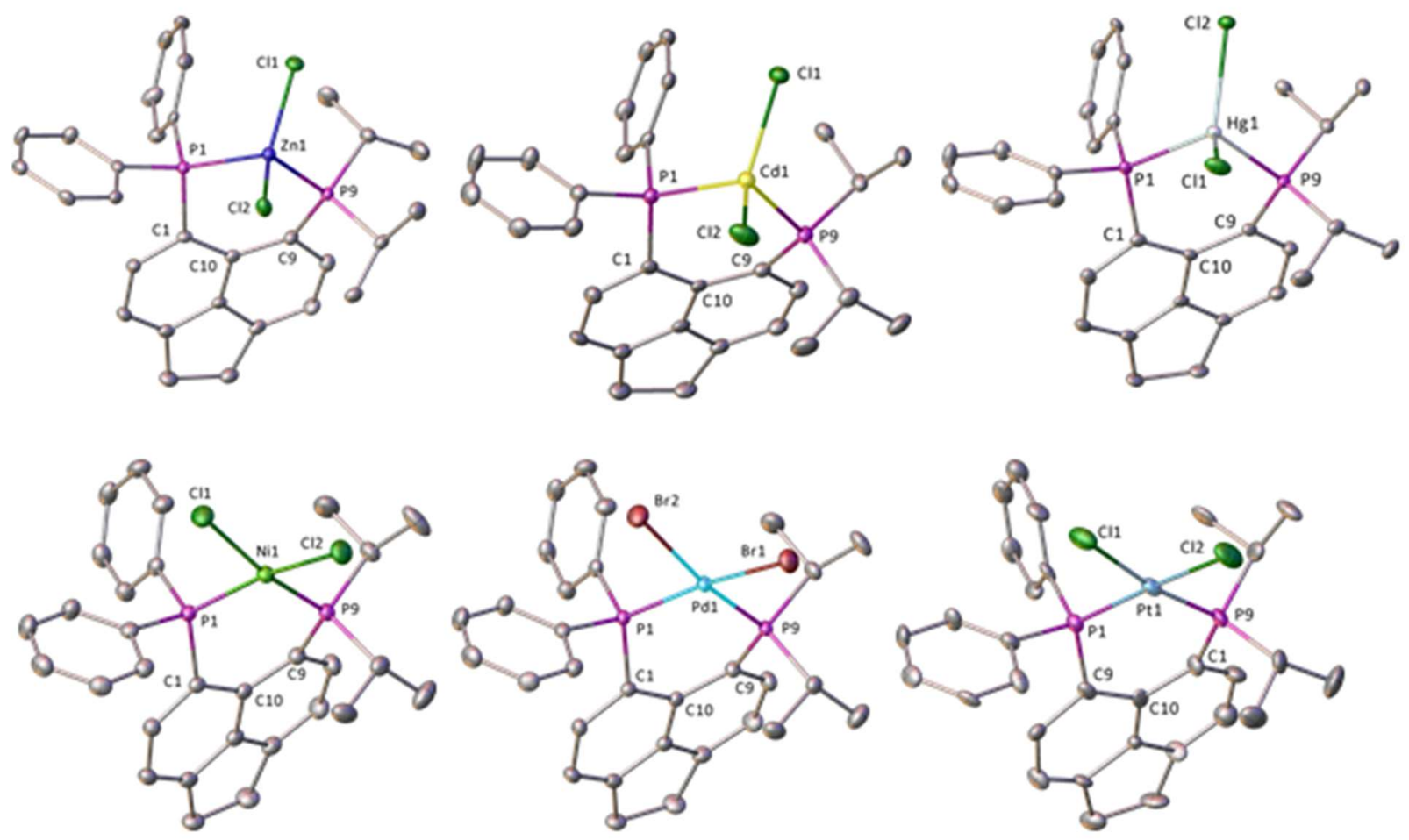

Figure 11: Crystal structures of [ $\left.\mathrm{LZnCl}_{2}\right],\left[\mathbf{L C d C l}{ }_{2}\right],\left[\mathrm{LHgCl}_{2}\right]$ (top) and [ $\left.\mathrm{LNiCl}_{2}\right],\left[\mathrm{LPdBr}_{2}\right],\left[\mathrm{LPtCl}_{2}\right]$ (bottom). Solvating molecules and hydrogen atoms are omitted for clarity. Thermal ellipsoids are plotted at the 40 $\%$ probability level.

In addition to the rather pronounced out-of-plane distortions of the ligand, the metal centres show deviations from the ideal square planar geometry. This is of interest especially for the nickel complex, as unusual magnetic properties were observed for this complex in the solution NMR (see above). The P1Ni1-P9 cis-angle is $92.99(2)^{\circ}$. A distinct tetrahedral distortion is observable with the trans bond angles of 165.54(2) (P1-Ni1-Cl2) and 164.95(2) (P9-Ni1-Cl1), with similar values for Pd and Pt complexes (167.45(3) to $\left.173.2(1)^{\circ}\right)$. Although these deviations are significant, they are not sufficiently pronounced for the structures to be considered as intermediate between tetrahedral and square planar, such as seen, for example, in $\mathrm{CuCl}_{4}{ }^{2-}$ anion, where trans angles of $c a .135-138^{\circ}$ have been observed..$^{43}$

For the group 10 series, the $\mathrm{Ph}_{2} \mathrm{P}-\mathrm{M}$ bond lengths are slightly shorter than the $i \mathrm{Pr}_{2} \mathrm{P}-\mathrm{M}$ bond lengths, correlating with an increase in $\pi$ back-bonding. In $\left[\mathrm{LPtCl}_{2}\right]$ the shorter P-Pt bond results in larger magnitude of $J_{\mathrm{PPt}}$ coupling. This indicates the coupling is not proportional only to the strength of the $\sigma$ component of the metal-phosphorus bond, but rather to the overall strength of the bonding (i.e. the product of $\sigma$ and $\pi$ interaction). 


\section{Group 11 Complexes [( $\left.\mathrm{LCuCl})_{2}\right],\left[\mathrm{L}_{2} \mathrm{Ag}\right] \mathrm{SbF}_{6}$ and $\left[\mathrm{L}^{\mathrm{O}} \mathrm{CuCl}_{2}\right]$}

The copper atom in the centrosymmetric dimer $\left[(\mathrm{LCuCl})_{2}\right]$ adopts a distorted tetrahedral geometry. A P $\ldots . P$ distance of $3.4206(18) \AA$ in $\left[(\mathrm{LCuCl})_{2}\right]$ is comparable to that in the tetrahedral coordinated group 12 series (Figure 12, Table 3). The P-Cu distances are crystallographically identical (2.2298(11) $\AA$ and 2.2286(13) $\AA$ ), which contrasts the observations made with the monomeric [LMX ${ }_{2}$ ] species discussed above.

In the crystal structure of $\left[\mathrm{L}_{2} \mathbf{A g}\right] \mathbf{S b F}_{6}$ two molecules of very similar geometry are present in the asymmetric unit. The silver centre adopts a distorted tetrahedral geometry, with $\mathrm{P}-\mathrm{Ag}-\mathrm{P}$ angles within each ligand being acute (P31-Ag1-P39 $\left.84.67(4)^{\circ}\right)$. This is compensated by the obtuse inter-ligand P-Ag$\mathrm{P}$ angles, such as P1-Ag1-P39 $\left(126.40(4)^{\circ}\right)$.
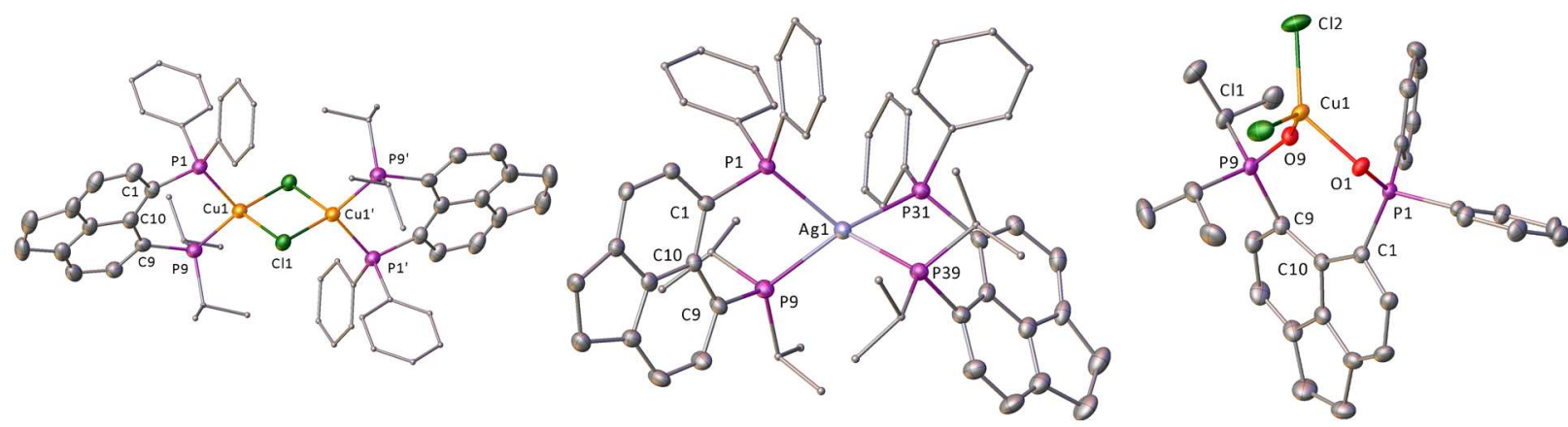

Figure 12: Crystal structures of $\left[(\mathbf{L C u C l})_{2}\right]$ (left), $\left[\mathrm{L}_{2} \mathrm{Ag}\right] \mathrm{SbF}_{6}$ (middle) and $\left[\mathrm{L}^{\mathrm{O}} \mathrm{CuCl}_{2}\right]$ (right). Solvating molecules $\left(\mathrm{CHCl}_{3}, \mathrm{MeOH}\right.$ and toluene, respectively) and hydrogen atoms are omitted, as are the $\mathrm{SbF}_{6}$ anion in $\left[\mathrm{L}_{2} \mathbf{A g}\right] \mathrm{SbF}_{6}$ and the second molecule in the asymmetric unit of $\left[\mathrm{L}^{\mathrm{O}} \mathrm{CuCl}_{2}\right]$. Thermal ellipsoids are plotted at the $40 \%$ probability level.

The distortions of the acenaphthene backbone in $\left[(\mathbf{L C u C l})_{2}\right]$ and $\left[\mathbf{L}_{2} \mathbf{A g}\right] \mathbf{S b F}_{6}$ are comparable to those seen in the tetrahedral Group $12\left[\mathrm{LMCl}_{2}\right]$ complexes (Table 3). The only exception to this is that the silver(I) atom is displaced further out of the acenaphthene plane than any other metal in this study $(1.168 \AA$ and $1.330 \AA$, respectively, in the two molecules in the asymmetric unit). This anomaly is likely to result from the significant steric clash of the isopropyl and phenyl groups arising from the two bis(phosphine) ligands $\mathbf{L}$ attached to a single metal atom.

The copper(II) complex of the dioxidised ligand $\left[\mathrm{L}^{\mathrm{O} 2} \mathrm{CuCl}_{2}\right]$ displays a tetrahedrally coordinated copper atom, forming an eight membered metallacycle (Figure 12). Attachment of the $\mathbf{L}^{\mathbf{0 2}}$ ligand in a $\mathrm{K}^{2}$ manner via two oxygen donor atoms results in the peri-region of the ligand backbone showing greater distortion, in terms of both in-plane and out-of-plane distortions, than in free $\mathbf{L}^{\mathbf{0 2}}$. These distortions are significantly larger than those seen in the tetrahedral complexes of ligand $\mathbf{L}$ (Table 3 ). 


\section{Cobalt Dichloride Complexes $\left[\mathrm{LCoCl}_{2}\right],\left[\mathrm{L}^{\circ} \mathrm{CoCl}_{2}\right]$ and $\left[\mathrm{L}^{\mathrm{O}} \mathrm{CoCl}_{2}\right]$}

Although the paramagnetism of the cobalt(II) centre prohibited collection of the relevant ${ }^{31} \mathrm{P}$ NMR spectra and hence evaluation of the P...P couplings, the series of the Co(II) complexes with $L, L^{0}$ and $\mathbf{L}^{\mathbf{0 2}}$ is still of interest from a structural point of view. In all three complexes, the cobalt(II) centre adopts a distorted tetrahedral geometry, with $\mathrm{P} 1 / \mathrm{O} 1-\mathrm{Co}-\mathrm{P9} / \mathrm{O} 9$ bond angles ranging from $83.6(2)^{\circ}$ in $\left[\mathrm{L}^{02} \mathrm{CoCl}_{2}\right]$ to $101.1(1)^{\circ}$ in $\left[{ }^{\circ} \mathrm{CoCl}_{2}\right]$ ) (Figure 13 and Table 3). The P...P distances increase from 3.367(2) $\AA$ in $\left[\mathrm{LCoCl}_{2}\right]$, to 3.663(2) $\AA$ in $\left[\mathrm{L}^{\circ} \mathrm{CoCl}_{2}\right]$ and 3.850 (3) $\AA$ in $\left[\mathrm{L}^{02} \mathrm{CoCl}_{2}\right]$. The out-of-plane distortions also increase upon oxidation of the phosphorus atom(s). This is documented by the peri-region torsion angles P9-C9 ‥C1-P1, which change dramatically from $2.4(3)^{\circ}$ in $\left[\mathrm{LCoCl}_{2}\right]$, to $42.2(3)^{\circ}$ in $\left[\mathrm{L}^{\circ} \mathrm{CoCl}_{2}\right]$ and $42.8(4)^{\circ}$ in $\left[\mathrm{L}^{\mathrm{O}} \mathrm{CoCl}_{2}\right]$.
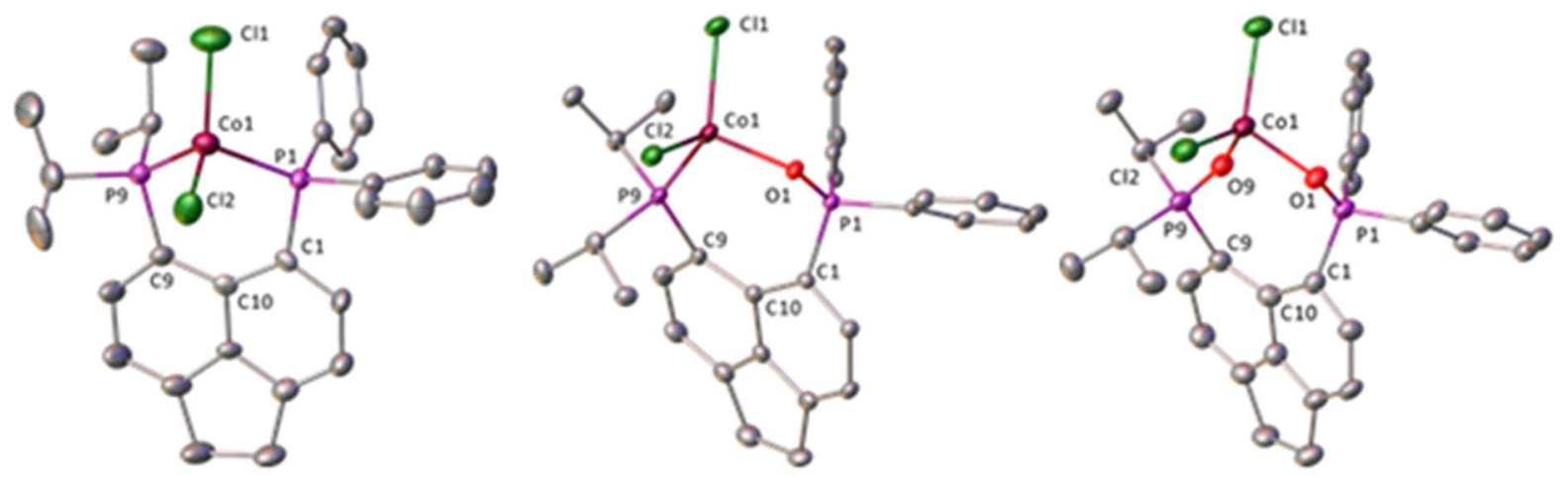

Figure 13: Views of the crystal structures of $\left[\mathrm{LCoCl}_{2}\right],\left[\mathrm{L}^{\circ} \mathrm{CoCl}_{2}\right]$ and $\left[\mathrm{L}^{\mathrm{O}} \mathrm{CoCl}_{2}\right]$. Solvating molecules and hydrogen atoms are omitted for clarity. All thermal ellipsoids are plotted at the $40 \%$ probability level. 
Table 3: Selected bond distances $(\AA)$ and angles $\left(^{\circ}\right)$ for the metal complexes of $\mathbf{L}, \mathbf{L}^{\mathbf{0}}$ and $\mathbf{L}^{\mathbf{0 2}}$.

\begin{tabular}{|c|c|c|c|c|c|c|c|c|c|c|c|c|}
\hline & $\begin{array}{c}{\left[\mathrm{LZnCl}_{2}\right]} \\
\cdot 0.5 \mathrm{CH}_{2} \mathrm{Cl}_{2}\end{array}$ & {$\left[\mathrm{LCdCl}_{2}\right]$} & {$\left[\mathrm{LHgCl}_{2}\right]$} & $\begin{array}{l}{\left[\mathrm{LNiCl}_{2}\right]} \\
\cdot \mathrm{CH}_{2} \mathrm{Cl}_{2}\end{array}$ & $\begin{array}{c}{\left[\mathrm{LPdBr}_{2}\right]} \\
\cdot \mathrm{CH}_{2} \mathrm{Cl}_{2}\end{array}$ & {$\left[\mathrm{LPtCl}_{2}\right]^{[\mathrm{b}]}$} & $\begin{array}{c}{\left[(\mathrm{LCuCl})_{2}\right]} \\
\cdot 2 \mathrm{CHCl}_{3}\end{array}$ & $\begin{array}{c}{\left[\mathrm{L}_{2} \mathrm{Ag}\right] \mathrm{SbF}_{6}^{[\mathrm{cc}]}} \\
\cdot \mathrm{CH}_{3} \mathrm{OH}\end{array}$ & {$\left[\mathrm{LCoCl}_{2}\right]$} & $\begin{array}{c}{\left[\mathrm{L}^{\circ} \mathrm{CoCl}_{2}\right]} \\
\cdot \mathrm{CH}_{3} \mathrm{CN}\end{array}$ & $\begin{array}{c}{\left[{ }^{\left[{ }^{02} \mathrm{CoCl}_{2}\right]}\right.} \\
\cdot \mathrm{CH}_{3} \mathrm{CN}\end{array}$ & $\begin{array}{c}{\left[\mathrm{L}^{\mathrm{O} 2} \mathrm{CuCl}_{2}\right]^{[\mathrm{d}]}} \\
.0 .5 \mathrm{C}_{7} \mathrm{H}_{8}\end{array}$ \\
\hline \multicolumn{13}{|c|}{ peri-region bond distances } \\
\hline 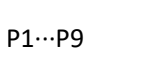 & $3.4725(12)$ & $3.5277(19)$ & $3.5923(16)$ & $3.1322(7)$ & $3.2208(11)$ & $3.213(6)$ & $3.4206(18)$ & $\begin{array}{c}3.4038(17) \\
{[3.3874(15)]}\end{array}$ & $3.367(2)$ & $3.663(2)$ & $3.850(3)$ & $\begin{array}{c}3.7594(16) \\
{[3.7775(16)]}\end{array}$ \\
\hline $\mathrm{P} 1 / 01-\mathrm{M}$ & $2.3970(8)$ & $2.5687(14)$ & $2.5128(10)$ & $2.1359(5)$ & $2.2216(8)$ & $2.203(4)$ & $2.2298(11)$ & $\begin{array}{c}2.5116(11) \\
{[2.5150(12)]}\end{array}$ & $2.3591(18)$ & $1.954(4)$ & $1.982(4)$ & $\begin{array}{c}1.972(3) \\
{[1.936(3)]}\end{array}$ \\
\hline P9/O9-M & $2.3714(9)$ & $2.5841(16)$ & $2.4896(11)$ & $2.1824(5)$ & $2.2692(8)$ & $2.236(4)$ & $2.2286(13)$ & $\begin{array}{c}2.5179(12) \\
{[2.5146(11)]}\end{array}$ & $2.3793(19)$ & $2.4727(17)$ & $1.976(5)$ & $\begin{array}{c}1.959(3) \\
{[1.951(3)]}\end{array}$ \\
\hline \multicolumn{13}{|c|}{ peri-region bond angles } \\
\hline $\begin{array}{l}\mathrm{P} 1 / \mathrm{O} 1-\mathrm{M}- \\
\mathrm{P} / \mathrm{O9}\end{array}$ & $93.47(3)$ & $86.41(3)$ & $91.97(3)$ & $92.99(2)$ & $91.64(3)$ & $92.8(1)$ & $100.21(5)$ & $\begin{array}{c}85.18(4) \\
{[84.67(4)]}\end{array}$ & $90.57(6)$ & 101.1(1) & $83.6(2)$ & $\begin{array}{c}83.9(1) \\
{[82.9(1)]}\end{array}$ \\
\hline Splay angle ${ }^{[a]}$ & $20.6(8)$ & $20.7(9)$ & $22.6(9)$ & $8.0(3)$ & $10.6(6)$ & $14(3)$ & 21(1) & $\begin{array}{c}20(1) \\
{[19(1)]}\end{array}$ & $23(1)$ & $21(1)$ & $26(1)$ & $\begin{array}{c}27.5(9) \\
{[26.1(9)]}\end{array}$ \\
\hline \multicolumn{13}{|c|}{ out-of-plane displacements[ ${ }^{[\mathrm{e}]}$} \\
\hline P1 & 0.525 & 0.774 & 0.796 & 0.751 & -0.790 & -0.689 & 0.527 & $\begin{array}{l}-0.338 \\
{[-0.494]}\end{array}$ & -0.011 & 0.888 & 0.896 & $\begin{array}{c}0.695 \\
{[0.805]}\end{array}$ \\
\hline P9 & -0.563 & -0.508 & -0.462 & -0.646 & 0.610 & 0.453 & -0.333 & $\begin{array}{c}0.499 \\
{[0.448]}\end{array}$ & 0.087 & -0.780 & -0.797 & $\begin{array}{l}-0.753 \\
{[-0.773]}\end{array}$ \\
\hline M & -0.768 & -0.319 & -0.235 & -0.183 & 0.134 & 0.215 & -0.381 & $\begin{array}{l}-1.168 \\
{[-1.330]}\end{array}$ & 1.252 & -0.758 & -0.799 & $\begin{array}{l}-1.120 \\
{[-0.804]}\end{array}$ \\
\hline \multicolumn{13}{|c|}{ peri-region torsion angles } \\
\hline $\begin{array}{l}\mathrm{P9}-\mathrm{C9} \\
\cdots \mathrm{C} 1-\mathrm{P} 1\end{array}$ & $28.9(2)$ & $34.0(2)$ & $33.4(2)$ & $36.69(8)$ & $36.8(1)$ & $28.6(7)$ & $20.2(2)$ & $\begin{array}{c}20.7(2) \\
{[22.3(2)]}\end{array}$ & $2.4(3)$ & $42.2(3)$ & $42.8(4)$ & $\begin{array}{c}36.2(2) \\
{[40.3(2)]}\end{array}$ \\
\hline
\end{tabular}

$\overline{[a]}$ Splay angle $=$ sum of the bay region angles -360 (see Figure S12 in supporting information. ${ }^{[b]}$ Ref. ${ }^{18} .{ }^{[c]}$ Values in square parentheses are for the 2 nd ligand molecule, where P1 is equivalent to P31, P9 to P39 and so forth.

${ }^{[d]}$ Values in square parentheses are for the $2^{\text {nd }}$ molecule in the asymmetric unit. ${ }^{[e]}$ Displacement from the acenaphthene mean plane. 


\section{Computational Studies}

In order to obtain further insight into the nature of the observed $J_{P P}$ couplings, we have performed Coupling Deformation Density (CDD) calculations. ${ }^{44}$ Calculations of this nature have proven very useful for visualising the pathways through which $J$ couplings connect the nuclei involved, and are particularly useful to distinguish between through-space and through-bond couplings, with the relative importance of different pathways judged by the intensities and volumes of the isosurfaces. ${ }^{45-46}$ The notion that $J_{\mathrm{PP}}$ coupling is occurring through-space in free $\mathbf{L}$, but through-bond in its metal complexes is confirmed as shown in the CDD plots in Figure 14. For free $L$, the path linking the two $P$ atoms directly (rather than via the $\mathrm{P}-\mathrm{C}$ and $\mathrm{C}-\mathrm{C}$ bonds that make a formal ${ }^{4} \mathrm{~J}$ coupling) is clearly seen (Figure 14 , left). In the zinc and nickel complexes, as representative examples, this coupling path clearly traverses along the bonds through the metal (Figure 14, middle and right).

The computed $J_{\mathrm{Pp}}$ coupling constants of free ligand $\mathbf{L}$ and selected metal complexes are collected in Table 4. While the observed coupling in $\left[\left(\mathrm{LCuCl}_{2}\right]\right.$ appears to be significantly underestimated at our level and not all trends are reproduced correctly, the general finding that substantial coupling between the $P$ atoms exist both in free ligand $\mathbf{L}$ and its metal complexes is well captured. Interestingly, upon going from the $\mathrm{d}^{10}$ systems ( $\mathrm{Zn}$ and Cu complexes) to the $\mathrm{d}^{8}$ complex $\left[\mathbf{L N i C l}_{2}\right]$, the $J_{\mathrm{PP}}$ value is predicted to change sign. It is well known that the sign of ${ }^{2} J_{\mathrm{PP}}$ in transition-metal diphosphines can be positive or negative, depending on the mutual orientation of the $\mathrm{P}$ nuclei as well as on the nature of the metal and the other ligands present. ${ }^{47-48}$
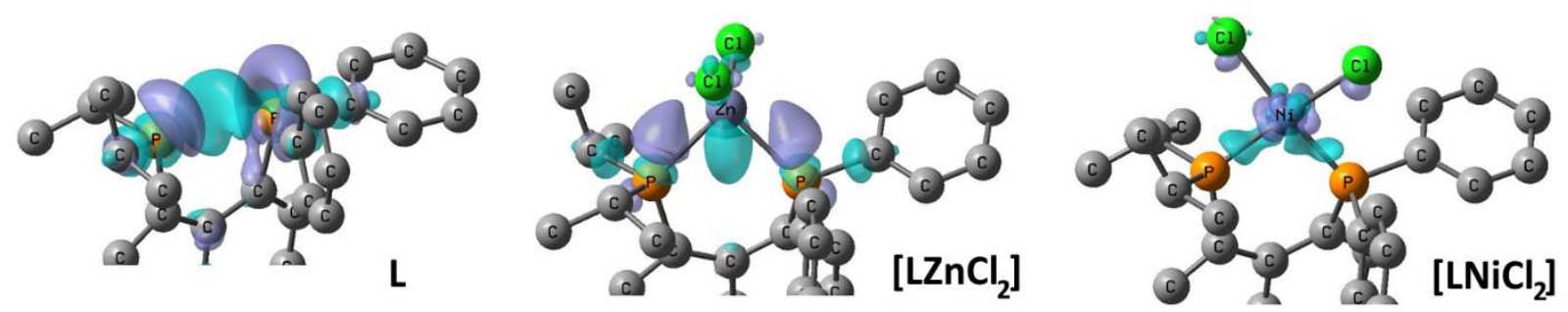

Figure 14: Plots of the coupling deformation density of free $\mathbf{L},\left[\mathrm{LZnCl}_{2}\right]$ and $\left[\mathrm{LNiCl}_{2}\right]$. Hydrogen atoms and parts of the acenaphthyl moieties omitted, isosurfaces plotted at the PP86 level for CDD $=0.2$ a.u.

Table 4 Computed (B3LYP/Wachters/IGLO-II" level) and experimental $J_{\mathrm{PP}}$ coupling constants for $\mathbf{L}$ and selected metal complexes (in $\mathrm{Hz}$ ).

\begin{tabular}{lcc}
\hline Compound & $J_{\mathrm{PP}}$ calculated $^{a}$ & $\left|J_{\mathrm{PP}}\right|$ experimental \\
\hline $\mathrm{L}$ & 210 & 180 \\
{$\left[\mathrm{LNiCl}_{2}\right]$} & -140 & 117 \\
{$\left[\left(\mathrm{LCuCl}_{2}\right]\right.$} & 160 & 215 \\
{$\left[\mathrm{LZnCl}_{2}\right]$} & 184 & 193 \\
\hline
\end{tabular}

${ }^{a}$ Dominated by the Fermi contact contributions (all other terms contribute less than $2 \mathrm{~Hz}$ ). 


\section{Conclusion}

We report a series of $d$-block metal complexes with a geometrically restrained heteroleptic bis(phosphine) ligand $\mathbf{L}$, a system with potential for significant through-space coupling. We conclude that in our peri-substituted system (and likely in other ones with similar potential for through-space coupling) the general notion that bridging the two phosphine donor atoms by a metal should lead to a significant increase of $J_{\mathrm{PP}}$, has limited validity. For example, coordination of zinc (in $\left[\mathrm{LZnCl}_{2}\right]$, tetrahedral geometry) leads to $J_{\mathrm{PP}}$ comparable to that found in the free ligand $\mathbf{L}\left(193.0 \mathrm{~Hz}\right.$ in $\left[\mathrm{LZnCl}_{2}\right]$ vs. $180.0 \mathrm{~Hz}$ in $\left.\mathbf{L}\right)$. More counterintuitively, on coordination to a square planar $\mathrm{d}^{8}$ metal centre $\left(\mathrm{Pd}^{\prime \prime}, \mathrm{Pt} \mathrm{t}^{\prime \prime}\right)$, the $J_{\mathrm{PP}}$ decreases significantly to 16.0 and $26.1 \mathrm{~Hz}$, respectively. This is despite the fact that the P..P separation in these complexes is comparable (3.100 $\AA$ in $\mathbf{L}$ vs. 3.213(6) in [ $\mathbf{L P t C l}_{2}$ ]. In the same fashion, coordination to an octahedral metal centre in $\left[\mathrm{LMo}(\mathrm{CO})_{4}\right]$ results in small magnitude of the $J_{\mathrm{Pp}}$ coupling $(33.5 \mathrm{~Hz}) .{ }^{18}$

Coupling Deformation Density calculations confirm the dominance of through-space contribution to the coupling in $\mathbf{L}$, which is highly dependent on oxidation state of phosphorus centres, diminishing with monoxidation or dioxidation.

In addition, an interesting cobalt-mediated highly selective aerobic monoxidation of the ligand has been observed, whilst nickel complex displayed interesting variable temperature solution NMR behaviour, presumably because of its paramagnetism at ambient temperatures.

\section{Associated Content}

Supporting Information

The Supporting Information is available free of charge on the ACS Publications website at DOI: xxx.

Full details of the synthetic procedures, ${ }^{31} \mathrm{P}$ NMR spectra, the crystallographic details relating to this work, and computational details

Crystallographic data (CIF)

The research data supporting this publication can be accessed at [DOI].

\section{Acknowledgements}

This work was financially supported by the EPSRC (EP/M506631/1, EP/L505079/1) and COST action SM1302 SIPs. The authors would like to thank the EPSRC UK National Mass Spectrometry Facility at Swansea University for the acquisition and processing of Mass Spectrometry Data. Lastly, B. A. C. and P. K. would like to thank I. L. J. Patterson for use of the UV-vis Spectrophotometer and the Johnson Matthey Magnetic Susceptibility Balance. M.B. would like to thank EaStCHEM and the School of Chemistry for support and $\mathrm{Dr} \mathrm{H}$. Früchtl for technical assistance with the computations; O. L. M. acknowledges financial support from the Grant Agency of the Ministry of Education of the Slovak Republic and Slovak Academy 
of Sciences VEGA (grant No. 2/0116/17) and from the Slovak Research and Development Agency (grant APVV-15-0726).

\section{Author Information}

Corresponding author

pk7@st-andrews.ac.uk

Notes:

The authors declare no competing financial interest.

\section{References}

1. Kilian, P.; Knight, F. R.; Woollins, J. D., Synthesis of ligands based on naphthalene peri-substituted by Group 15 and 16 elements and their coordination chemistry. Coordination Chemistry Reviews 2011, 255 (11-12), 1387-1413.

2. Jackson, R. D.; James, S.; Orpen, A. G.; Pringle, P. G., 1,8-Bis(diphenylphosphino)naphthalene: A rigid chelating, diphosphine analogue of proton sponge. Journal of Organometallic Chemistry 1993, 458 (1-2), C3-C4.

3. Batsanov, S. S., Van der Waals Radii of Elements. Inorganic Materials 2001, 37 (9), 871-885.

4. Bregman, F. R.; Ernsting, J. M.; Müller, F.; Boele, M. D. K.; van der Veen, L. A.; Elsevier, C. J., 103RhNMR spectroscopy of some hydridorhodiumbis(carbonyl)diphosphine compounds. Journal of Organometallic Chemistry 1999, 592 (2), 306-311.

5. Karaçar, A.; Thönnessen, H.; Jones, P. G.; Bartsch, R.; Schmutzler, R., 1,8Bis(phosphino)naphthalenes: Synthesis and molecular structures. Heteroatom Chemistry 1997, 8 (6), 539-550.

6. Jones, P. G.; Thönnessen, H.; Karaçar, A.; Schmutzler, R., 1,8Bis(dimethylphosphino)naphthalene: an unusual case of pseudosymmetry. Acta Crystallographica Section C: Crystal Structure Communications 1997, 53, 1119-1122.

7. Karaçar, A.; Thönnessen, H.; Jones, P. G.; Bartsch, R.; Schmutzler, R., 1,8Bis(phosphanyl)naphthalenes: $\quad$ 1,8-Bis[(diethylamino)phosphanyl]-naphthalene, 1,8Bis(dichlorophosphany)naphthalene, and 1, 3-Dichloro-2,-3-dihydro-1,3-dioxo-2-oxa-1,3diphosphaphenalene. Chemische Berichte 1997, 130 (10), 1485-1489.

8. Karaçar, A.; Freytag, M.; Thönnessen, H.; Jones, P. G.; Bartsch, R.; Schmutzler, R., Preparation and structures of 1-dimethylamino-2-bis(dimethylamino)- and 1-chloro-2-bis(diethylamino)-1-phospha-2phosphonium acenaphthene: the first examples of the 1,2-dihydro-1,2-diphospha-acenaphthene ring system. Journal of Organometallic Chemistry 2002, 643-644 (0), 68-80. 
9. Karaçar, A.; Freytag, M.; Jones, P. G.; Bartsch, R.; Schmutzler, R., Platinum(II) Complexes of PChiral 1, 8-Bis(diorganophosphino)naphthalenes; Crystal Structures of dmfppn, rac-[PtCl2(dmfppn)], and rac-[PtCl2(dtbppn)] (dmfppn = 1, 8-di(methyl-pentafluorophenylphosphino)naphthalene and dtbppn = 1, 8-di(tert-butylphenylphosphino)naphthalene). Zeitschrift für anorganische und allgemeine Chemie 2002, $628(3), 533-544$.

10. Costa, T.; Schmidbaur, H., 1,8-Naphthalindiylbis(dimethylphosphan): Konsequenzen sterischer Hinderung für Methylierung und Borylierung. Chemische Berichte 1982, 115 (4), 1374-1378.

11. Kilian, P.; Knight, F. R.; Woollins, J. D., Naphthalene and Related Systems peri-Substituted by Group 15 and 16 Elements. Chem. Eur. J. 2011, 17 (8), 2302-2328.

12. Gamper, S. F.; Schmidbaur, H., Synthesis and Molecular Structure of Heterocycles Containing two Phosphorus(V) Centers Bridged by Two-Coordinate Phosphorus and Arsenic. Chemische Berichte 1993, $126(3), 601-604$.

13. Tanaka, N.; Kasai, T., Reactions of 5,6-Dilithioacenaphthene- $N, N, N^{\prime}, N^{\prime}$-Tetramethyl-1,2ethanediamine Complex with a -Diketones. I.cis-Directing 1:1 Cyclic Additions with Acyclic and Cyclic a -Diketones and Related Compounds. Bulletin of the Chemical Society of Japan 1981, 54 (10), 3020-3025. 14. Wawrzyniak, P.; Fuller, A. L.; Slawin, A. M. Z.; Kilian, P., Intramolecular Phosphine-Phosphine Donor-Acceptor Complexes. Inorganic Chemistry 2009, 48 (6), 2500-2506.

15. Chalmers, B. A.; Bühl, M.; Athukorala Arachchige, K. S.; Slawin, A. M. Z.; Kilian, P., Geometrically Enforced Donor-Facilitated Dehydrocoupling Leading to an Isolable Arsanylidine-Phosphorane. Journal of the American Chemical Society 2014, 136 (17), 6247-6250.

16. Athukorala Arachchige, K. S.; Sanz Camacho, P.; Ray, M. J.; Chalmers, B. A.; Knight, F. R.; Ashbrook, S. E.; Bühl, M.; Kilian, P.; Slawin, A. M. Z.; Woollins, J. D., Sterically Restricted Tin Phosphines, Stabilized by Weak Intramolecular Donor-Acceptor Interactions. Organometallics 2014, 33 (10), 2424-2433.

17. Nordheider, A.; Hupf, E.; Chalmers, B. A.; Knight, F. R.; Bühl, M.; Mebs, S.; Chęcińska, L.; Lork, E.; Camacho, P. S.; Ashbrook, S. E.; Athukorala Arachchige, K. S.; Cordes, D. B.; Slawin, A. M. Z.; Beckmann, J.; Woollins, J. D., Peri-Substituted Phosphorus-Tellurium Systems-An Experimental and Theoretical Investigation of the P...Te through-Space Interaction. Inorganic Chemistry 2015, 54 (5), 2435-2446.

18. Chalmers, B. A.; Athukorala Arachchige, K. S.; Prentis, J. K. D.; Knight, F. R.; Kilian, P.; Slawin, A. M. Z.; Woollins, J. D., Sterically Encumbered Tin and Phosphorus peri-Substituted Acenaphthenes. Inorganic Chemistry 2014, 53 (16), 8795-8808.

19. Kilian, P.; Slawin, A. M. Z.; Woollins, J. D., A structural study of 1,8-bis(dimethyl phosphonito) naphthalene and related crowded chalcogeno derivatives. Dalton Transactions 2003, (20), 3876-3885. 20. Kilian, P.; Slawin, A. M. Z., 1,8,9-Substituted anthracenes, intramolecular phosphine donor stabilized metaphosphonate and phosphenium. Dalton Transactions 2007, (30), 3289-3296. 
21. Wawrzyniak, P.; Slawin, A. M. Z.; Woollins, J. D.; Kilian, P., Syntheses and characterization of bis(trifluoromethyl)phosphino naphthalenes and acenaphthenes. Dalton Transactions 2010, 39 (1), 8592.

22. Ray, M. J.; Randall, R. A. M.; Arachchige, K. S. A.; Slawin, A. M. Z.; Buehl, M.; Lebl, T.; Kilian, P., Synthetic, Structural, NMR, and Computational Study of a Geminally Bis(peri-substituted) Tridentate Phosphine and Its Chalcogenides and Transition-Metal Complexes. Inorganic Chemistry 2013, 52 (8), 4346-4359.

23. Ray, M. J.; Slawin, A. M. Z.; Buehl, M.; Kilian, P., peri-Substituted Phosphino-Phosphonium Salts: Synthesis and Reactivity. Organometallics 2013, 32 (12), 3481-3492.

24. Taylor, L. J.; Bühl, M.; Wawrzyniak, P.; Chalmers, B. A.; Woollins, J. D.; Slawin, A. M. Z.; Fuller, A. L.; Kilian, P., Hydride Abstraction and Deprotonation - an Efficient Route to Low Coordinate Phosphorus and Arsenic Species. European Journal of Inorganic Chemistry 2016, 2016 (5), 659-666.

25. Taylor, L. J.; Surgenor, B. A.; Wawrzyniak, P.; Ray, M. J.; Cordes, D. B.; Slawin, A. M. Z.; Kilian, P., Spontaneous dehydrocoupling in peri-substituted phosphine-borane adducts. Dalton Transactions 2016, 45 (5), 1976-1986.

26. Hupf, E.; Lork, E.; Mebs, S.; Chęcińska, L.; Beckmann, J., Probing Donor-Acceptor Interactions in peri-Substituted Diphenylphosphinoacenaphthyl-Element Dichlorides of Group 13 and 15 Elements. Organometallics 2014, 33 (24), 7247-7259.

27. Bertrand, R. D.; Ogilvie, F. B.; Verkade, J. G., Signs of phosphorus-phosphorus coupling constants in coordination compounds. J. Am. Chem. Soc. 1970, 92 (7), 1908-1915.

28. Hierso, J.-C.; Fihri, A.; Ivanov, V. V.; Hanquet, B.; Pirio, N.; Donnadieu, B.; Rebière, B.; Amardeil, R.; Meunier, P., "Through-Space" Nuclear Spin-Spin JPP Coupling in Tetraphosphine Ferrocenyl Derivatives: A 31P NMR and X-ray Structure Correlation Study for Coordination Complexes. Journal of the American Chemical Society 2004, 126 (35), 11077-11087.

29. Hierso, J.-C., Indirect Nonbonded Nuclear Spin-Spin Coupling: A Guide for the Recognition and Understanding of "Through-Space" NMR J Constants in Small Organic, Organometallic, and Coordination Compounds. Chemical Reviews 2014, 114 (9), 4838-4867.

30. Sgarbossa, P.; Pizzo, E.; Scarso, A.; Sbovata, S. M.; Michelin, R. A.; Mozzon, M.; Strukul, G.; Benetollo, F., Bis-phosphine monoxide platinum(II) and palladium(II) cationic complexes as Lewis acid catalysts in Diels-Alder and sulfoxidation reactions. J. Organomet. Chem. 2006, 691 (17), 3659-3666.

31. Côté, A.; Lindsay, V. N. G.; Charette, A. B., Application of the Chiral Bis(phosphine) Monoxide Ligand to Catalytic Enantioselective Addition of Dialkylzinc Reagents to $\beta$-Nitroalkenes. Org. Lett. 2007, 9 (1), 85-87. 
32. Boezio, A. A.; Pytkowicz, J.; Côté, A.; Charette, A. B., Asymmetric, Catalytic Synthesis of $\alpha$-Chiral Amines Using a Novel Bis(phosphine) Monoxide Chiral Ligand. J. Am. Chem. Soc. 2003, 125 (47), 1426014261.

33. Landert, H.; Spindler, F.; Wyss, A.; Blaser, H.-U.; Pugin, B.; Ribourduoille, Y.; Gschwend, B.; Ramalingam, B.; Pfaltz, A., Chiral Mixed Secondary Phosphine-Oxide-Phosphines: High-Performing and Easily Accessible Ligands for Asymmetric Hydrogenation. Angew. Chem. Int. Ed. 2010, 49 (38), 6873-6876. 34. Cyr, P. W.; Rettig, S. J.; Patrick, B. O.; James, B. R., Formation of Ruthenium(II)-Bis(phosphine) Monoxide Complexes from the Bis(phosphine) Precursors: BINAP-Monoxide (BINAPO) as a Six-Electron (P,O,n2- Naphthyl) Donor. Organometallics 2002, 21 (22), 4672-4679.

35. Mallory, F. B.; Mallory, C. W.; Butler, K. E.; Lewis, M. B.; Xia, A. Q.; Luzik, E. D.; Fredenburgh, L. E.; Ramanjulu, M. M.; Van, Q. N.; Francl, M. M.; Freed, D. A.; Wray, C. C.; Hann, C.; Nerz-Stormes, M.; Carroll, P. J.; Chirlian, L. E., Nuclear Spin-Spin Coupling via Nonbonded Interactions. 8.1 The Distance Dependence of Through-Space Fluorine-Fluorine Coupling. Journal of the American Chemical Society 2000, 122 (17), 4108-4116.

36. Knight, F. R.; Fuller, A. L.; Bühl, M.; Slawin, A. M. Z.; Woollins, J. D., Sterically Crowded periSubstituted Naphthalene Phosphines and their PV Derivatives. Chemistry - A European Journal 2010, 16 (25), 7617-7634.

37. Grim, S. O.; Lui, P. J.; Keiter, R. L., Phosphorus-31 nuclear magnetic resonance study of tertiary phosphine-mercury(II) halide complexes. Inorganic Chemistry 1974, 13 (2), 342-345.

38. Steffen, W. L.; Palenik, G. J., Infrared and crystal structure study of .sigma. vs. .pi. bonding in tetrahedral zinc(II) complexes. Crystal and molecular structures of dichlorobis(4-substituted pyridine)zinc(II) complexes. Inorg. Chem. 1977, 16 (5), 1119-1127.

39. Ong, J. H. L.; Nataro, C.; Golen, J. A.; Rheingold, A. L., Electrochemistry of Late Transition Metal Complexes Containing the Ligand 1,1'-Bis(diisopropylphosphino)ferrocene (dippf). Organometallics 2003, 22 (24), 5027-5032.

40. Orpen, A. G.; Connelly, N. G., Structural systematics: the role of P-A .sigma.* orbitals in metalphosphorus .pi.-bonding in redox-related pairs of $M-P A 3$ complexes $(A=R, A r, O R ; R=$ alkyl). Organometallics 1990, 9 (4), 1206-1210.

41. Willis, J. B.; Mellor, D. P., The Magnetic Susceptibility of Some Nickel Complexes in Solution. J. Am. Chem. Soc. 1947, 69 (6), 1237-1240.

42. Schultz, M.; Plessow, P. N.; Rominger, F.; Weigel, L., Structure, magnetism and colour in simple bis(phosphine)nickel(II) dihalide complexes: an experimental and theoretical investigation. Acta Crystallogr C 2013, 69 (Pt 12), 1437-47.

43. Halvorson, K. E.; Patterson, C.; Willett, R. D., Structures of bis(4-aminopyridinium) tetrachlorocuprate(II) monohydrate, [C5H7N2]2[CuCl4].H2O and bis(2-amino-3-hydroxypyridinium) 
tetrachlorocuprate(II), [C5H7N2O]2[CuCl4]: correlation of CuCl42- geometry with hydrogen bonding and electronic structure. Acta Crystallographica Section B 1990, 46 (4), 508-519.

44. Malkina, O. L.; Malkin, V. G., Visualization of Nuclear Spin-Spin Coupling Pathways by Real-Space Functions. Angewandte Chemie International Edition 2003, 42 (36), 4335-4338.

45. Kaupp, M.; Patrakov, A.; Reviakine, R.; Malkina, O. L., Understanding the Conformational Dependence of Spin-Spin Coupling Constants: Through-Bond and Through-Space J(31P,31P) Coupling in Tetraphosphane-1,4-diides [M(L)x]2[P4R4]. Chemistry - A European Journal 2005, 11 (9), 2773-2782.

46. Křístková, A.; Asher, J. R.; Malkin, V. G.; Malkina, O. L., Indirect Nuclear 15N-15N Scalar Coupling through a Hydrogen Bond: Dependence on Structural Parameters Studied by Quantum Chemistry Tools. The Journal of Physical Chemistry A 2013, 117 (38), 9235-9244.

47. Ogilvie, F. B.; Jenkins, J. M.; Verkade, J. G., 31P-31P spin-spin coupling in complexes containing two phosphorus ligands. Journal of the American Chemical Society 1970, 92 (7), 1916-1923.

48. Fontaine, X. L. R.; Kennedy, J. D.; Shaw, B. L.; Vila, J. M., Determination of the relative signs of $2 \mathrm{~J}(31 \mathrm{P}-31 \mathrm{P})$ in complexes of tungsten(0) and molybdenum(0) using two-dimensional [31P-31P]-COSY-45 nuclear magnetic resonance chemical shift correlation. Journal of the Chemical Society, Dalton Transactions 1987, (10), 2401-2405. 


\section{TOC Graphics and Synopsis}

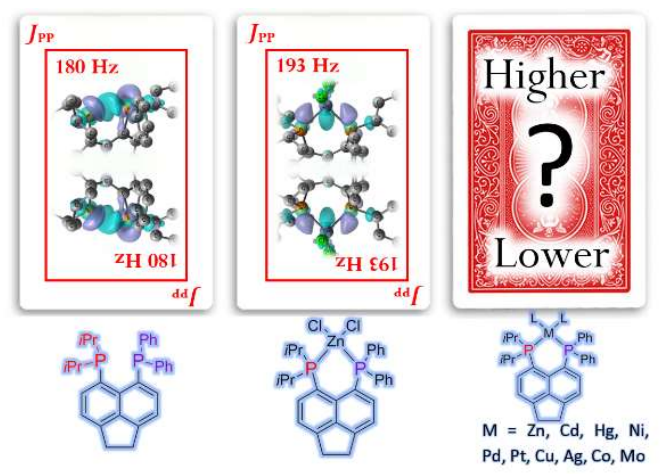

Magnitudes of J(PP) coupling in a non-symmetrical bis(phosphine) ligand with large through space interaction $(180 \mathrm{~Hz})$ are correlated with those in a series of its representative late $d$-block metal complexes. For some metals, the J(PP) magnitude decreases significantly on complexation (i.e. formation of P-M-P bridge), with the smallest one observed for Pd complex $\left({ }^{2} \mathrm{~J}(\mathrm{PP})=16 \mathrm{~Hz}\right)$. 